\title{
REVIEW
}

\section{Extrapulmonary poorly differentiated NECs, including molecular and immune aspects}

\author{
Mairéad G McNamara1,2, Jean-Yves Scoazec ${ }^{3,4}$ and Thomas Walter 5 \\ 1Department of Medical Oncology, The Christie NHS Foundation Trust, Manchester, UK \\ 2Division of Cancer Sciences, University of Manchester, Manchester, UK \\ ${ }^{3}$ Department of Pathology, Gustave Roussy Cancer Campus, Villejuif, France \\ ${ }^{4}$ Université Paris Sud, Faculté de Médecine de Bicêtre, Le Kremlin-Bicêtre, France \\ ${ }^{5}$ Department of Gastroenterology and Medical Oncology, Edouard Herriot Hospital, Hospices Civils de Lyon, Lyon, France
}

Correspondence should be addressed to M G McNamara: Mairead.McNamara@christie.nhs.uk

\begin{abstract}
Patients with extrapulmonary poorly differentiated neuroendocrine carcinomas (EP-PD-NECs) have a poor prognosis. Surgery is offered for those with localised disease, but the majority of patients present with advanced disease. Treatment strategies adopted are analogous to that of high grade NECs of the lung, with platinum/etoposide-based regimens advocated in the first-line setting for advanced disease. There is no standard second-line therapy. Research into their molecular and immune pathways may pave the way for novel drug discovery. The molecular drivers of NEC are best identified in small cell lung carcinoma, which present with near universal genomic alterations in TP53 and RB1. The genetics of EP-PD-NEC remain poorly understood; TP53, KRAS, PIK3CA/PTEN and BRAF mutations have been identified, with alterations in the BRCA pathway reported additionally in small cell NEC of the cervix and absence of argininosuccinate synthetase 1 expression in NEC of the urinary bladder. The use of cell lines and patient-derived xenografts (PDX) to predict response to treatment in NEC and the emergence of alternative biomarkers, such as circulating tumour cells and cell-free DNA, will also be explored. Despite limited published data on the immune microenvironment of EP-NEC, there are a number of clinical trials investigating the use of immune-targeted agents in this disease category, with conflicting emerging data from studies thus far. This review will summarise the treatment and available molecular and immune data in this under researched diagnosis and may stimulate the direction of future exploratory studies.
\end{abstract}

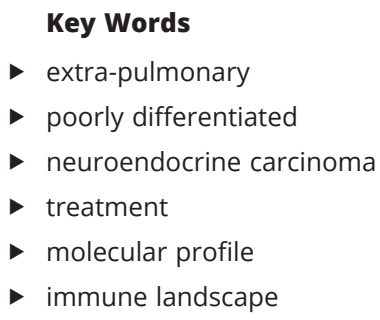

Endocrine-Related Cance (2020) 27, R219-R238

\section{Introduction}

High grade neuroendocrine carcinomas (NECs) are usually defined by the combination of a poorly differentiated tumour cell morphology and evidence of high proliferative activity, evaluated either directly through the mitotic index and/or Ki-67 or indirectly through the presence of tumour necrosis (Bosman et al. 2010). According to tumour cell morphology, two subtypes of NEC are recognised (Dasari et al. 2018).
The small cell type is defined by the presence of smallto medium-sized tumour cells, characterised by an elongated, hyperchromatic nucleus, devoid of visible nucleoli. The large cell type, first described in the lung, but later identified in most other body sites, is defined by the presence of medium- to large-sized tumour cells, containing a large, ovoid, vesicular nucleus with well visible nucleoli (George et al. 2015, 2018). c) 2020 Society for Endocrinology Published by Bioscientifica Ltd. Printed in Great Britain 
Irrespective of their subtype, patients with NEC usually present with disseminated disease and carry a very poor prognosis (Sorbye et al. 2013). The current first-line treatment in the advanced setting is a platinum/etoposide combination (Casas et al. 1997, Garcia-Carbonero et al. 2016); on progression, there is no consensus for secondline treatment (Garcia-Carbonero et al. 2016, McNamara et al. 2019).

There has been recent progress in the pathological diagnosis of high grade neuroendocrine neoplasms (NENs) (Lloyd et al. 2017, Rindi et al. 2018a) and in the description of their molecular and immune landscapes (Sahnane et al. 2015, Vijayvergia et al. 2016, Morgan et al . 2019). However, so far, there has been little translation of these new data into clinical management and treatment. Nevertheless, it could be expected that better knowledge of the molecular and immune characteristics of NEC could pave the way for the identification of novel biomarkers of diagnostic, prognostic and predictive relevance, which could potentially enable improvements in patient management and new therapeutic strategy development.

This review will focus on extra-pulmonary NENs, where there is a large clinical and therapeutic unmet need and where very limited progress in patient management has been made in nearly four decades. Secondary NECs developing in treatment-resistant adenocarcinomas such as in the prostate or in the lung will be excluded, as will some well-defined entities closely related to NEC, but of different pathogenesis and thus requiring more extensive systematic review and therefore beyond the scope of this manuscript, such as mixed neuroendocrine non-neuroendocrine neoplasms (see Frizziero et al. 2020 for summary of literature) and Merkel cell carcinoma. The current state of the art practice in diagnosis and management will also be briefly mentioned. Recent reports on molecular and immune features will then be discussed and finally how these novel data might translate into new tools for improving patient management and treatment, in the era of precision medicine, molecularly driven therapeutic strategies and immunotherapy.

\section{Extra-pulmonary NEC: current basis for patient diagnosis, management and treatment}

\section{Diagnosis and terminology}

In a recent series from the National Cancer Institute's Surveillance, Epidemiology and End Results (SEER) program, 14,732 of 162,983 cases of NEC were extrapulmonary (EP-NEC); of these, 5509 were gastrointestinal (37.4\%), 4151 were of unknown primary (28.2\%) and 5072 were of other sites (34.4\%), including the head and neck region and the genito-urinary tract (Dasari et al. 2018). There are differences in diagnosis and terminology according to the site of the primary, and this might have consequences for patient management (Klöppel 2017). For example, the morphological diagnosis of high grade pancreatic NENs is challenging, especially when limited pathological material may be available, and so may require additional sections together with immunohistochemical staining for surrogate markers of known genotypes of well differentiated neuroendocrine tumours (NETs) and poorly differentiated NEC (Tang et al. 2016). See section on 'Current prognostic and predictive markers' for further details.

High grade, poorly differentiated NECs account for approximately $10 \%$ of all gastrointestinal NENs (Janson et al. 2010). According to the World Health Organisation (WHO) classification, the diagnosis of digestive NEC is based only on tumour cell morphology; nearly all cases are grade 3 (G3) according to the grading system of digestive NENs (i.e. mitotic index $>20$ and Ki-67 index $>20 \%$ ) (Bosman et al. 2010), but this is not required for the definitive diagnosis. As in the lung, two subtypes are recognised (Dasari et al. 2018), but the large cell subtype has been formally recognised in the WHO classification only in 2010; until this date, only the small cell subtype was identified. However, large cell NEC is much more frequent in the GEP sphere than in other body sites (Dasari et al. 2018). In the study by Dasari et al. (2018), it was reported that there were significant differences in survival of patients with a NEC diagnosis according to morphological subtype $(P<0.001)$, with small cell histology being associated with worse median and 5-year survival at most primary sites (Dasari et al. 2018). In a multicentre retrospective study investigating the impact of small cell vs non-small cell morphology on outcomes in patients with EP-NEC (poorly differentiated), it was reported that those patients with NEC with non-small cell morphology, compared to small cell, had a lower Ki-67 and were less likely to benefit from first-line platinum/ etoposide chemotherapy in the advanced setting (Zaninotto et al. 2020).

There are striking differences in the distribution of NEC along the digestive tract; NEC is the main type of NEN encountered in the oesophagus and the anal region $(>90 \%)$, is frequent in the ampullary region, the colon and the rectum and rare in other digestive locations, 
such as the pancreas, duodenum, the small intestine and the appendix (Brenner et al. 2004, Walter et al. 2017, Rindi et al. 2018a). It should also be highlighted that it is now widely accepted that not all high grade digestive NENs are poorly differentiated, and therefore, they should not be labelled and treated as NEC. It has been recognised that some G3 digestive NENs are well-differentiated and that their identification is important, since they carry a better prognosis than true NEC and might justify different therapeutic strategies. This new tumour category, termed neuroendocrine tumour (NET) G3, has been formally recognised, first in the 2017 revision of the WHO classification of pancreatic NENs (Lloyd et al. 2017) and then in the 2019 revision of the WHO classification of all digestive NENs (Nagtegaal et al. 2020). It is likely that this tumour category also exists in other body sites, but without formal recognition at this time (Rindi et al. 2018b).

High grade NENs of the head and neck region are defined by the same diagnostic criteria as that in the lung: poorly differentiated tumour cell morphology, mitotic index $>10 / 2 \mathrm{~mm}^{2}$ and usually with the presence of necrosis (Uccella et al. 2017). As in other body sites, two subtypes are recognised, small cell and large cell. However, the terminology used in the 2016 revision of the WHO classification is different from that employed in the other body sites. All head and neck NENs are termed 'neuroendocrine carcinomas' (uncommon head and neck malignancies), because of their high malignant potential; three categories are recognised: well-, moderately and poorly differentiated. Only the poorly differentiated category is equivalent to what is called NEC in the other body sites (Uccella et al. 2017), with treatment varying, consisting of neoadjuvant chemoradiotherapy \pm surgical excision \pm post-operative chemoradiotherapy (Bouzbouz et al. 2020). One meta-analysis of 701 cases of sinonasal NEC reported that the most important predictor of 5 -year disease-specific survival (DSS) was tumour type; it was worse for those with sinonasal small cell carcinoma (46.1\%) vs those with well- or moderately differentiated tumours (70.2\%) (van der Laan et al. 2016).

In the other body sites, high grade NENs are more loosely defined than in the lung, the GEP tract and those of head and neck origin. Most of them are labelled as 'small cell' carcinoma, especially in the genito-urinary tract (Gupta et al. 2018), even if a closer look confirms the existence of tumours identifiable as large cell NEC in other body sites. Large cell NEC of the prostate is a rare entity, and nearly all patients with primary de novo large cell NEC of the prostate present at a late stage and have a poor prognosis, despite systemic chemotherapy (Tu et al. 2019).

It is also important to mention that a uniform criteria for demonstrating the neuroendocrine nature of a poorly differentiated carcinoma is not available. In WHO classifications, the only precise criteria are given for large cell carcinoma of the lung, which could be termed 'neuroendocrine' when at least $10 \%$ of tumour cells express one of the following neuroendocrine markers: synaptophysin, chromogranin A or complementaritydetermining region 56 (CD56) (Travis et al. 2015). For small cell and large cell carcinomas of other sites, the expression of only one (in lung and in head and neck), or at least two, including synaptophysin (in GEP NENs), of the above markers in a 'significant' but undefined proportion of tumour cells is required (Lloyd et al. 2017). This means that the term 'neuroendocrine carcinoma' is less well defined than it seems and that it may be different from one body site to another.

\section{Clinical and therapeutic issues}

Most patients with EP-NEC, irrespective of their primary site, present with metastatic disease and have poor survival (Dasari et al. 2018). This is well exemplified by GEP-NEC, in which large clinical series are available. More than two-thirds of patients with GEP-NEC have distant metastases at the time of diagnosis (Sorbye et al. 2013, Walter et al. 2017). Survival is poor, ranging from 38 months in patients with localised disease to 5 months in the metastatic setting (Sorbye et al. 2014). It may be as low as 1 month in those receiving best supportive care alone in the metastatic setting (Sorbye et al. 2013). In a population-based retrospective study in the Netherlands, which included 1544 cases (1045 with EP-NEC and 499 with NEC of unknown primary), the overall 5-year relative survival was $38 \%$ for patients with local/regional disease $(n=447)$ and $7 \%$ for patients with extensive disease $(n=582)$. For patients with NEC of unknown primary $(n=499)$, the 5-year relative survival was 6\% (van der Zwan et al. 2018).

Surgery, with the potential for cure, is recommended for localised disease, and given the high relapse rate, platinum-based adjuvant chemotherapy is advised (Casas et al. 1997, Garcia-Carbonero et al. 2016) \pm radiotherapy, as appropriate (Garcia-Carbonero et al. 2016). To date, systemic therapy does not differ according to location of primary site. In patients with locoregional unresectable disease, locoregional radiotherapy with chemotherapy 
could be considered (Garcia-Carbonero et al. 2016). In the advanced setting, systemic therapy is recommended, analogous to that of pulmonary NEC, with platinum-based chemotherapy combined with etoposide advocated in the first-line setting, with a reported response rate (RR) of $67 \%$ in one study (Moertel et al. 1991) (acknowledging that RR in this study was determined by clinical examination; however, this was the first study to support platinum-based treatment in the first-line advanced setting for patients with EP-PD-NEC), but around $31-58 \%$ in more recent publications (Sorbye et al. 2013, 2014, Walter et al. 2017, Frizziero et al. 2019). Radiotherapy may also be considered for symptom control (localised bone metastasis or brain) (Garcia-Carbonero et al. 2016).

There is no standard endorsed second-line treatment in the advanced setting for patients with EP-NEC. Re-treatment with a platinum/etoposide combination may be considered in patients that achieved a response to up-front treatment and progressed after a treatment break of at least 3 months, provided that there are no contraindications to re-challenge with platinum-based therapy, such as neurotoxicity or ototoxicity (GarciaCarbonero et al. 2016). In the NORDIC NEC study (Sorbye et al. 2013), of 305 patients, 100 (33\%) received secondline chemotherapy, with 35 receiving temozolomidebased therapy (at least two other studies have also reported the use of temozolomide in the second-line setting (Welin et al. 2011, Olsen et al. 2012)) and 20 taxotere-based chemotherapy; 31 patients (10\%) received third-line therapy (Sorbye et al. 2013). In a French cohort, first-, second- and third-line palliative chemotherapies were given in 176 (69\%), 100 (40\%) and 51 (20\%) patients, respectively; mainly 5-fluorouracil (5-FU)/irinotecan $(n=72)$ and 5-FU/oxaliplatin $(n=33)$ regimens in the post-first-line chemotherapy setting (Walter et al. 2017). Some other second-line regimens that have been used in small retrospective series include topotecan (RR: 0\%) (Olsen et al. 2014), 5-FU/irinotecan (RR: 24-31\%) (Hentic et al. 2012, Walter et al. 2017) and 5-FU/oxaliplatin (RR: 16-29\%) (Hadoux et al. 2015, Walter et al. 2017), with a median reported progression-free survival (PFS) ranging from 2.1-4.5 months and a median overall survival (OS) ranging from 3.2-18 months (where the latter OS was calculated from date of diagnosis of NEC to death (Hentic et al. 2012)). In a systematic review and meta-analysis of second-line treatment in 595 patients with advanced EP-NEC, the median RR reported was 18\% (range 0-50; $0 \%$ for single-agent everolimus, temozolomide, topotecan; 50\% with amrubicin), the median PFS was 2.5 months (range 1.2-6.0) and median OS was 7.6 months (range 3.2-22) (McNamara et al. 2019). Prospective trials are needed (Walter et al. 2018 (NCT02820857), Craig et al. 2020 (NCT03837977)).

\section{Current prognostic and predictive markers}

In GEP-NEC, the most common clinical factors reported, to date, that are negatively associated with survival were: poor Eastern Cooperative Oncology Group Performance Score (ECOG PS) (Sorbye et al. 2013, Lamarca et al. 2017, Walter et al. 2017) and stage/presence of liver metastases (Lamarca et al. 2017, Walter et al. 2017, Dasari et al. 2018). Adverse biochemical markers include: lactate dehydrogenase (LDH) (Sorbye et al. 2013, Freis et al. 2017, Lamarca et al. 2017, Walter et al. 2017), as in many aggressive neoplasms, but also, somewhat inconsistently, high platelet count (Sorbye et al. 2013), high alkaline phosphatase (ALK) (Lamarca et al. 2017), aspartate aminotransferase (Freis et al. 2017) and neuronspecific enolase (NSE) (Sorbye et al. 2013, Lamarca et al. 2017, Walter et al. 2017). High Ki-67 index has also been proposed as an adverse histological prognostic factor. Sorbye et al. reported that patients with G3 GEP-NEN with a Ki-67 $>55 \%$ had a better RR ( $42 \%$ vs $15 \%$ ) to systemic treatment, but worse survival (10 vs 14 months) than patients with a Ki-67 <55\% (Sorbye et al. 2013).

Alese et al. reviewed a large series of patients (identified between 2004 and 2013) with NEC $(n=1861)$ from the National Cancer Database, United States, and reported that treatment at an academic centre, age $<65$ years, and use of chemotherapy, were associated with improved survival (multi-agent was associated with superior survival compared with monotherapy, which was superior to no chemotherapy) (Alese et al. 2019). Another study derived a prognostic score (scoring from 0-6 points for 5 variables) for OS in 313 patients (all stages) with GEP-NEC. The five baseline variables included were ECOG PS, presence of liver metastases, ALK, LDH and Ki-67. The score was prognostic for OS on multivariable analysis $(P<0.001)$, and was validated in an external and prospective validation cohort, with two groups identified with incremental risk of death (group A: 0-2 points with good prognosis: median OS 19.4 months, and group B: 3-6 points with poor prognosis: median OS 5.2 months) (Lamarca et al. 2017).

The potential clinical importance of immunoreactive p53 protein in tumour tissue was reported from 124 patients with locally advanced or metastatic GEP-NECs treated with platinum-based chemotherapy from the Nordic NEC registry (Ali et al. 2017). 
The authors concluded that p53 expression could not be correlated with clinical outcome, but in patients with colorectal NECs, p53 expression was correlated with shorter PFS and OS, and studies are needed to explore its prognostic significance further. In a study of 33 cases of grade 3 NENs of the pancreas, loss of death domain-associated protein (DAXX) or ATP-dependent helicase ATRX (ATRX) protein expression defined well differentiated NETs and abnormal p53, Rb and SMAD4 expression signified poorly differentiated NEC (Tang et al. 2016). The disease-specific survival reported was 75 months and 11 months for the well-differentiated neuroendocrine tumour and poorly differentiated NEC group, respectively (Tang et al. 2016).

\section{Molecular and immune profile of extrapulmonary NECs: recent results}

In recent years, there has been accumulating data on the molecular profile of high grade NENs (Girardi et al. 2017). In addition, their immune profiles have been investigated.

\section{Molecular profiling in EP-NEC}

Recent data have shown that small cell NEC is associated with a highly distinctive molecular signature, characterised by the bi-allelic inactivation of both TP53 and RB1, as a result of various mechanisms, from mutations to large chromosomal rearrangements. First documented in the lung (George et al. 2015, 2018), this molecular signature has subsequently been confirmed in all body sites, including the digestive tract (Jesinghaus et al. 2017), the pancreas (Yachida et al. 2012, Hijioka et al. 2017, Konukiewitz et al. 2017, 2018), the head and neck region (Goyal et al. 2014, Wasserman et al. 2019), the genitourinary tract (Chang et al. 2018, Shen et al. 2018) and the uterine cervix (Frumovitz et al. 2016, Xing et al. 2018). This does not mean that other molecular alterations could not be found in small cell NEC. For instance, the NOTCH pathway is altered in about $25 \%$ of lung small cell NEC and in some EP-NECs (Xing et al. 2018). Frequent alterations in the phosphatidylinositol 3-kinase/phosphatase and tensin homologue/mammalian target of rapamycin (PI3K/PTEN/mTOR) pathway can be detected in some body sites such as the uterine cervix (Frumovitz et al. 2016, Cho et al. 2017, Xing et al. 2018). Cervical NECs may be associated with human papillomavirus (HPV), especially HPV18, and most will stain positive for p16, with the immunohistochemistry markers synaptophysin and CD56 being the most sensitive (Salvo et al. 2019). Targeted next-generation sequencing of ten cases of small cell NEC of the uterine cervix (nine hysterectomy specimens and one biopsy) also identified genetic alterations involving the breast cancer (BRCA) pathway (Xing et al. 2018). In the first-line advanced setting in patients with advanced NEC of the cervix, cisplatin combined with etoposide is favoured, and a combination of topotecan, paclitaxel, and bevacizumab has been described as a treatment option in the second-line setting (Salvo et al. 2019). The 5-year survival rate has been reported as $36 \%$, with a median overall survival ranging between 22 and 25 months (Salvo et al. 2019) (Table 1).

The genomics of large cell NEC is more complex and heterogeneous than that of small cell NEC. In several body sites, it has now been demonstrated that the category, as morphologically defined, can be associated with at least two distinct types of molecular signatures, with an overall comparable proportion of cases: (1) a 'small cell NEClike' signature, characterised by the double inactivation of TP53 and RB1 and (2) a 'carcinoma-like' signature, with the same profile of molecular alterations as in nonneuroendocrine carcinomas of the same location (George et al. 2015, 2018, Rekhtman et al. 2016). This molecular heterogeneity has been unambiguously documented in the lung (George et al. 2015, 2018, Rekhtman et al. 2016). In the GEP arena, most of the available studies have included not only 'pure' NECs, but also mixed neuroendocrine-non neuroendocrine neoplasms. Mixed neuroendocrine non-neuroendocrine neoplasms from the gastro-entero-pancreatic tract, by definition, contain a neuroendocrine and an exocrine component, each of them present in at least 30\% of the tumour mass and are malignant. It is an aggressive entity with a highgrade neuroendocrine component in the majority of cases and is associated with poor survival outcomes close to those of pure NECs (Frizziero et al. 2020). In several studies, it is therefore difficult to determine whether the molecular alterations reported were found in 'pure' NECs, in the high grade neuroendocrine component of a mixed tumour, or even in a whole mixed tumour without distinction between its components. Despite these possible pitfalls, it might be assumed that, in the colon, rectum, pancreas and the stomach, a significant proportion of tumours histologically diagnosed as 'large cell NEC' harbour molecular abnormalities usually found in adenocarcinomas of the same location. Colorectal NECs might harbour mutations in KRAS (20-30\%), BRAF (from 7 to $60 \%$ according to the series), adenomatous 


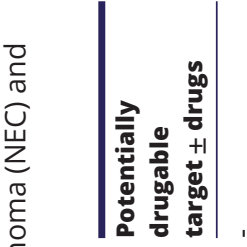

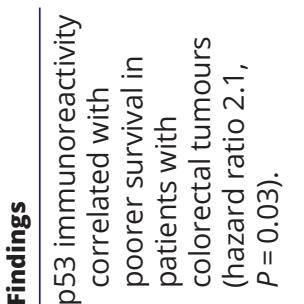

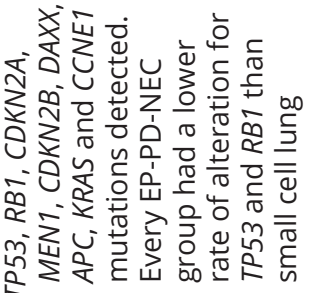

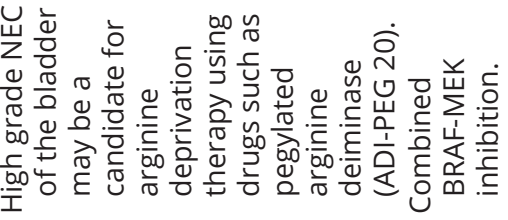

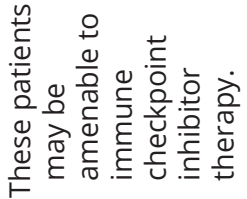

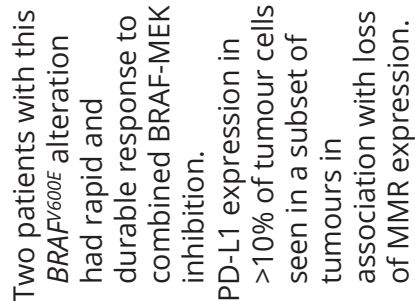

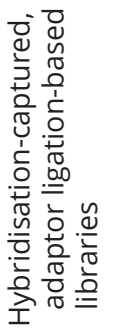

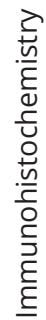

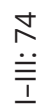
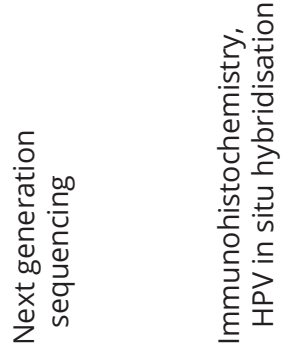

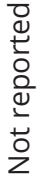

울
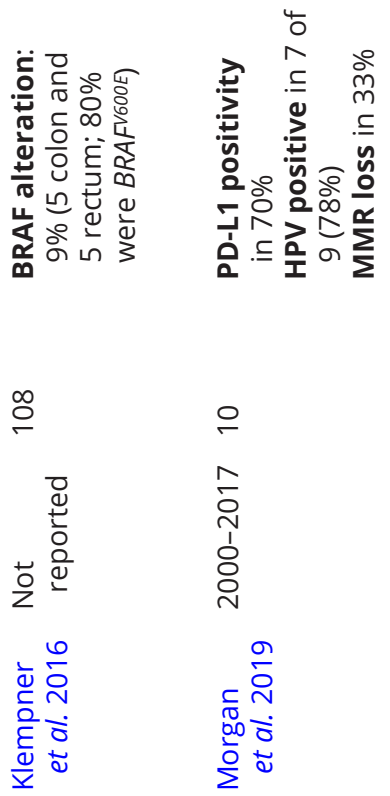

우<smiles></smiles> 

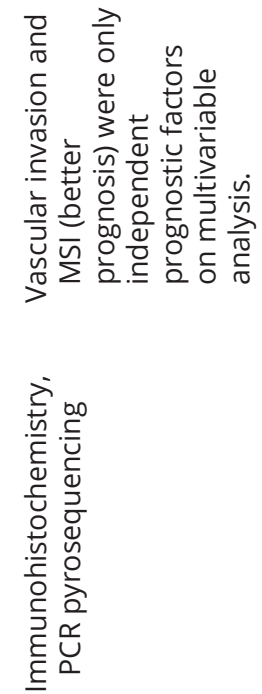

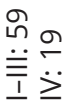

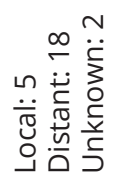

는

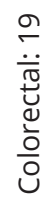

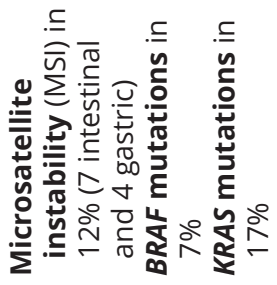

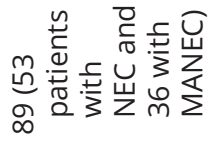

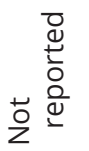

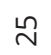

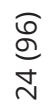

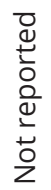
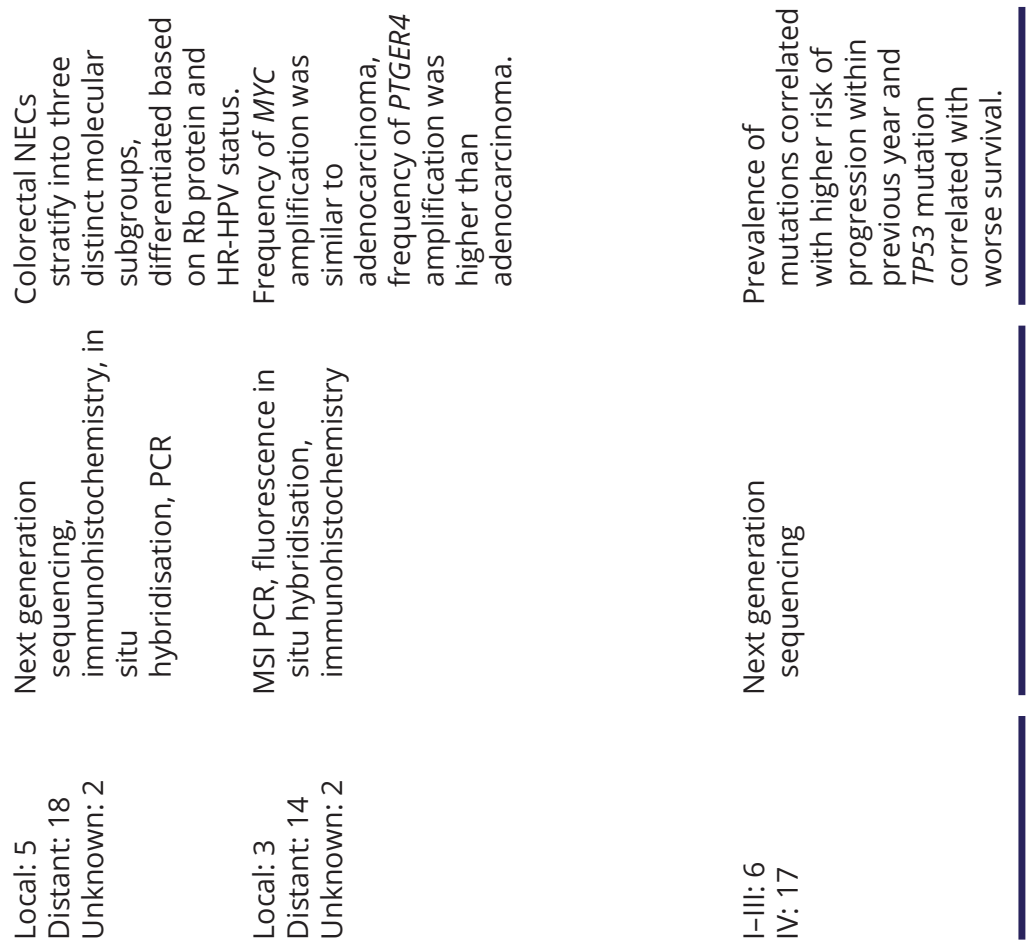

$\stackrel{\varphi}{\stackrel{亠}{\perp} \stackrel{一}{\perp}}$
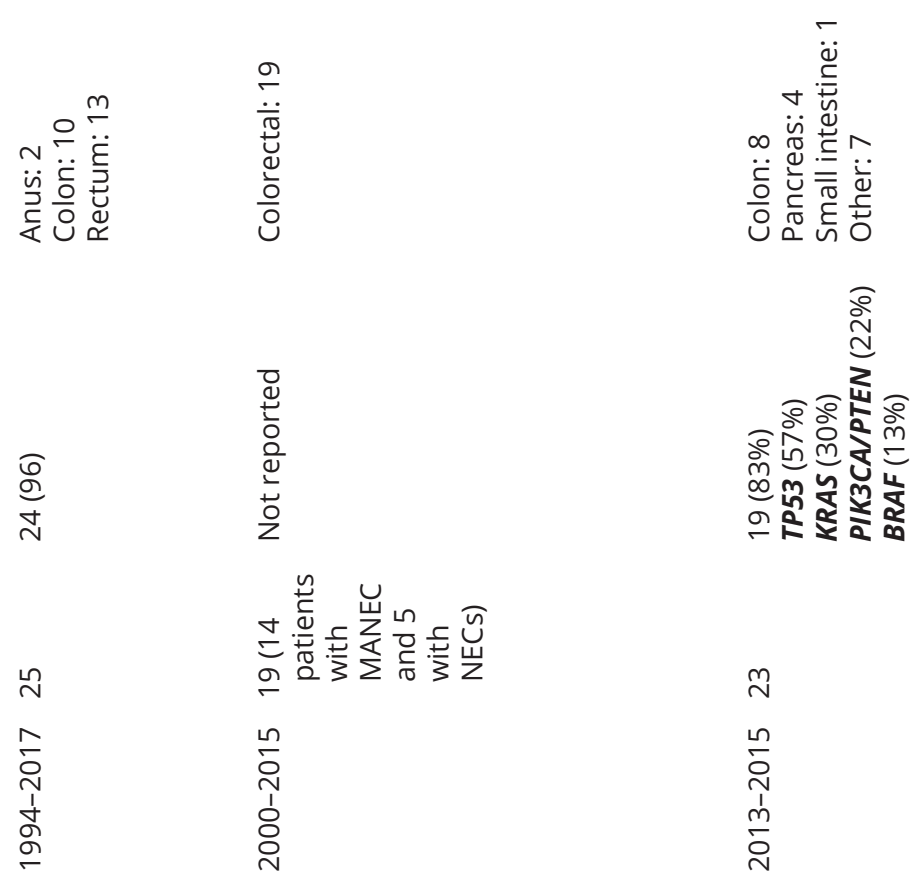

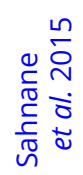

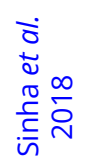

$\stackrel{m}{\sim}$

吕

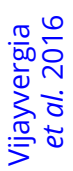




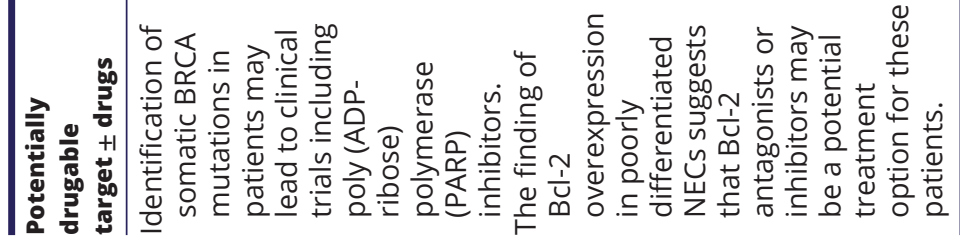
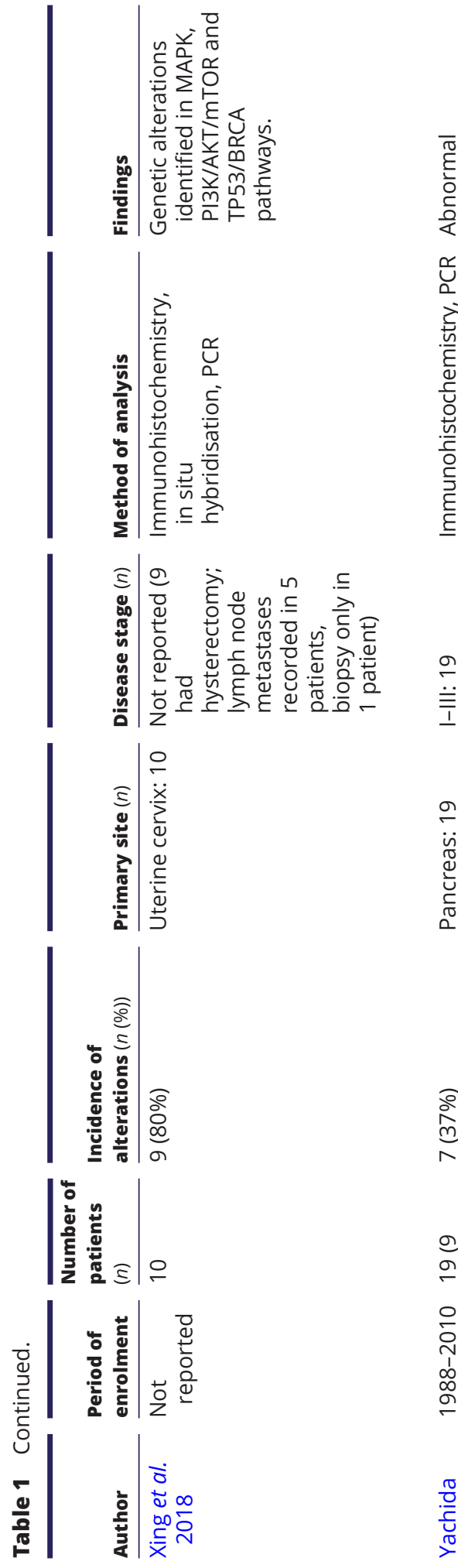

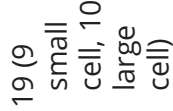

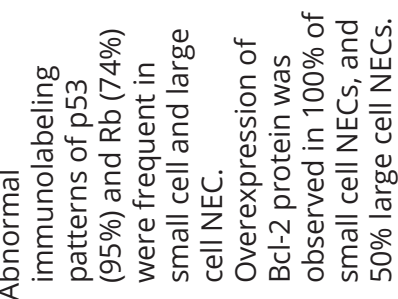

원

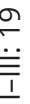

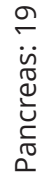

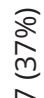

0
$\stackrel{0}{2}$
1
0
0
0

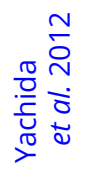

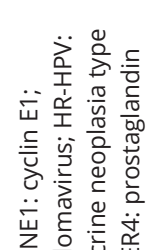

论

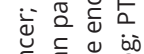

든 들 응 응

它

造斑䒓空

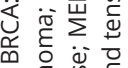

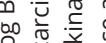

응

व

产 旁离

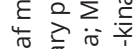

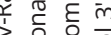

这它部

远

齐.

西

든

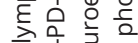

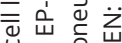

ตे

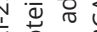

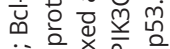

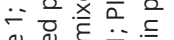

峁

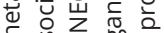

究依全

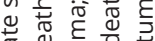

ᄃ व 웡

齐贾

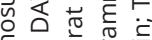

过

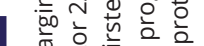

不

岁空安定

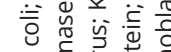

늘

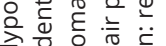

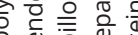

잉

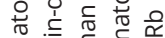

है

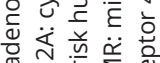

(3) 
polyposis coli (APC), PIK3CA or PTEN (up to 25\%), as well as MYC amplifications (Alitalo et al. 1983, Karkouche et al. 2012, Takizawa et al. 2015, Hammond et al. 2016, Klempner et al. 2016, Olevian et al. 2016, Jesinghaus et al. 2017, Idrees et al. 2018, Sinha et al. 2018). Some cases of pancreatic NECs harbour mutations in KRAS or SMAD4 (Kimura et al. 2016, Konukiewitz et al. 2018).

A potentially interesting alteration is the acquisition of microsatellite instability (MSI) by GEP NEC. The frequency is variable according to the series, from 0 to more than 10\% (Arnold et al. 2008). One of the most detailed studies is that of Sahnane et al., who investigated the incidence of MSI in 89 cases of GEP NECs and mixed adenoneuroendocrine carcinomas (MANECs) (53 NECs and 36 MANECs) (6 oesophageal, 77 gastrointestinal, 3 pancreatic and 3 gallbladder) (Sahnane et al. 2015); MSI was observed in 11 NEC/MANECs (12.4\%) (7 intestinal and 4 gastric). A BRAF mutation was identified in 6 of 88 cases (7\%) and KRAS mutations were identified in 15 cases (17\%); BRAF mutations were associated with MSI $(P<0.0008)$, while KRAS status did not correlate with any clinicopathological or molecular features (Sahnane et al. 2015). It was concluded that MSI identifies a subset of gastric and intestinal NECs/MANECs with distinct biology and a better prognosis; vascular invasion $(P=0.0003)$ and MSI $(P=0.0084)$ were identified as the only independent prognostic factors on multivariable analysis (Sahnane et al. 2015). A high incidence of MSI phenotype, higher than $30 \%$, has also been recently reported in small cell NEC of the uterine cervix (Morgan et al. 2019).

The recent progress in molecular profiling of small and large cell NEC has also underlined the striking molecular differences existing between well- and poorly differentiated NENs. This is particularly obvious in the GEP arena where well-differentiated NETs usually harbour no mutation in TP53 or RB1, while poorly differentiated NECs show none of the mutations found with a high incidence in their well-differentiated counterparts (such as mutations in multiple endocrine neoplasia type 1 (MEN1), ATRX and DAXX in the pancreas) (Yachida et al. 2012).

In 2016, Bergsland et al. examined the genomic alterations (using 192 cancer-related genes) of 867 NECs, including 593 small cell lung cancer samples and 274 EP-NECs (123 pancreas, 92 colon and 59 others from the oesophagus, stomach and small intestine (stage not stated) (Bergsland et al. 2016). Only TP53 crossed a $15 \%$ threshold in every group; MEN1 and DAXX were genes with alterations in $>15 \%$, specific to the pancreas, while APC and KRAS were altered in $>15 \%$, specific to the colon, whereas Cyclin E1 (CCNE1) was altered in $>15 \%$ of the 'other' gastrointestinal primary NECs. A lower rate of alterations in TP53 and RB1 were reported in all EP-NECs when compared to small cell lung cancer. The authors concluded that optimal therapy for EP-NECs may be site specific and different from small cell lung cancer (Bergsland et al. 2016).

\section{The immune context in EP-NECs}

The immune context, including the use of selected immune checkpoint targeted agents, has recently been explored, mainly in pulmonary NECs, but also in some extra-pulmonary tumours. In a study where 94 cases of pulmonary $(n=61)$ and extra pulmonary $(n=33)$ small cell NECs were analysed by immunohistochemistry for programmed cell death protein 1 (PD-1) and programmed death-ligand 1 (PD-L1) protein expression, PD-L1 was expressed in tumour-infiltrating macrophages and was correlated with tumour-infiltrating lymphocytes (Schultheis et al. 2015). The available data on the immune environment or the use of immunotherapy in patients with EP-NECs is limited. Morgan et al. reported that PD-L1 expression (predominantly focal) was present in $70 \%$ of ten cases of SCNEC of the uterine cervix (eight of whom received platinum/etoposide chemotherapy, one received radiotherapy alone and one best supportive care) (Morgan et al. 2019).

Indirect evidence for a hyperimmune state in some cases of NEC has been provided by molecular analysis. A high tumour mutational load (or burden) has been detected in lung NECs (Peifer et al. 2012, Rudin et al. 2012), but also in several types of EP-NECs (Sharabi et al. 2017, Chang et al. 2018, Salem et al. 2018).

\section{New perspectives for diagnosis, management and treatment}

\section{New diagnostic and predictive markers}

The translation of NEC molecular profiling into clinical practice may be made easier by the fact that most of the main and most constant genetic abnormalities associated with EP-NEC, that is, mutations in TP53 and RB1 genes, can be screened for using immunohistochemistry. Mutations in the TP53 gene are usually, while not consistently, associated with the accumulation of the abnormal protein within the nucleus of altered cells, making it detectable by conventional anti-p53 antibodies (Konukiewitz etal. 2017). 
In contrast, in the normal state, the p53 protein is expressed at very low levels, well below the sensitivity threshold of conventional immunohistochemistry. A strong and uniform nuclear labelling of tumour cells by anti-p53 antibodies is therefore suggestive of the presence of TP53 mutations. Mutations in RB1 genes are usually associated with a loss of expression of the corresponding protein in altered cells, which can be easily detected by conventional immunohistochemistry (Konukiewitz et al. 2017).

The demonstration of p53 accumulation and $\mathrm{Rb}$ loss in tumour cells has therefore been proposed in the recent WHO classifications as a useful tool to strengthen a diagnosis of NEC, as opposed to NET, including NET G3, which are constantly p53 negative and Rb positive (Lloyd et al. 2017). This has also been reported in a study analysing the histological and molecular properties of gastroenteropancreatic high grade NENs (15 grade 3 NETs and 39 NECs) (Busico et al. 2019). The sensitivity and specificity of this approach remains to be validated in large series, but the published results are encouraging (Basturk et al. 2014, Konukiewitz et al. 2017).

$\mathrm{Rb}$ loss might also prove to be a predictive marker of response to platinum salts in NECs. Some studies, in both pulmonary (Derks et al. 2018) and EP-NECs (Terashima et al. 2012), suggest that Rb loss in NEC may be associated with a better response to standard treatment. These results need to be validated in larger, prospective, multicentre studies.

\section{New therapeutic perspectives}

The three main perspectives are: (1) actionable molecular abnormalities, (2) identification of cellular targets and (3) immunotherapy.

$B R A F$ mutations, so frequently found in NECs, could be actionable. A dramatic response has been reported to combination BRAF-mitogen-activated protein kinase kinase (MEK) inhibition in two cases of metastatic rectal NEC, refractory to standard therapy (Klempner et al. 2016). Urinary BRAFV600E circulating tumour DNA monitoring correlated with disease response, and it was concluded that BRAFV600E may be an oncogenic driver responsive to BRAF-MEK combination therapy in this disease site (Klempner et al. 2016). Capdevila et al. have recently reported that NEC from the colon and colorectal carcinomas are similar in their mutational repertoire, with NEC from the colon being particularly enriched in BRAFV600E mutations (Capdevila et al. 2020). They concluded that BRAFV600E mutant colon NEC may benefit from BRAF inhibition in monotherapy, or with the addition of anti-EGF receptor (EGFR) antibodies, instead of MEK inhibitors for efficient blockade of acquired resistance (Capdevila et al. 2020).

Interestingly, a recent study has reported the efficacy and safety of the monoclonal antibody against vascular endothelial growth factor receptor 2 (VEGFR2), ramucirumab, combined with chemotherapy in patients with pre-treated metastatic gastric NEC $(n=13)$. The authors concluded that the ramucirumab/chemotherapy combination demonstrated promising activity, without severe or unexpected safety issues and may be due to higher VEGF receptor 2 (VEGFR2) expression in gastric NEC (Mishima et al. 2018). This may be an avenue for further therapeutic research.

Additional potential cellular targets in EP-NECs have been identified, such as in breast NEC (which is rare), farletuzumab and mirvetuximab soravtansine (FOLR1), sacituzumab govitecan (TROP-2) and HDAC inhibitors (H3K36Me3) (Vranic et al. 2019). Another study reported that nuclear and cytoplasmic thymidylate synthase, nuclear and cytoplasmic neuron-specific enolase and nuclear p27 were significantly overexpressed in neuroendocrine breast carcinoma $(P<0.01)$; cytoplasmic somatostatin receptor-2A (SSTR-2A) expression was associated with better distant disease-free survival $(P=0.013)$, cytoplasmic menin expression with worse relapse-free survival $(P=0.022)$ and nuclear p27 with longer breast cancer-specific survival $(P=0.022)$, compared with invasive ductal carcinomas (Roininen et al. 2019). Others targets of potential relevance are now detailed. Gupta et al. have reported on argininosuccinate synthetase (ASS1) expression, assessed by immunohistochemistry, in 74 patients who had radical cystectomy for NEC of the urinary bladder (63 small cell, 5 large cell and 6 mixed morphology) (Gupta et al. 2018). It was reported that 58 patients (78\%) had absent ASS1 expression, including all patients with large cell and mixed morphology. The 10-year survival from disease-specific death was not statistically significant between ASS1-expressing and deficient cases $(P=0.75)$. The authors hypothesised that arginine deprivation therapy may offer therapeutic benefit in these patients (Gupta et al. 2018), but validation studies would be needed.

The possible indications and relevance of immunotherapy in NECs, especially in cases with high mutational burden and/or MSI phenotype, are currently under investigation, prompted by the success encountered in Merkel cell carcinoma (cutaneous), an entity closely related to NEC.
(C) 2020 Society for Endocrinology Published by Bioscientifica Ltd. Printed in Great Britain 

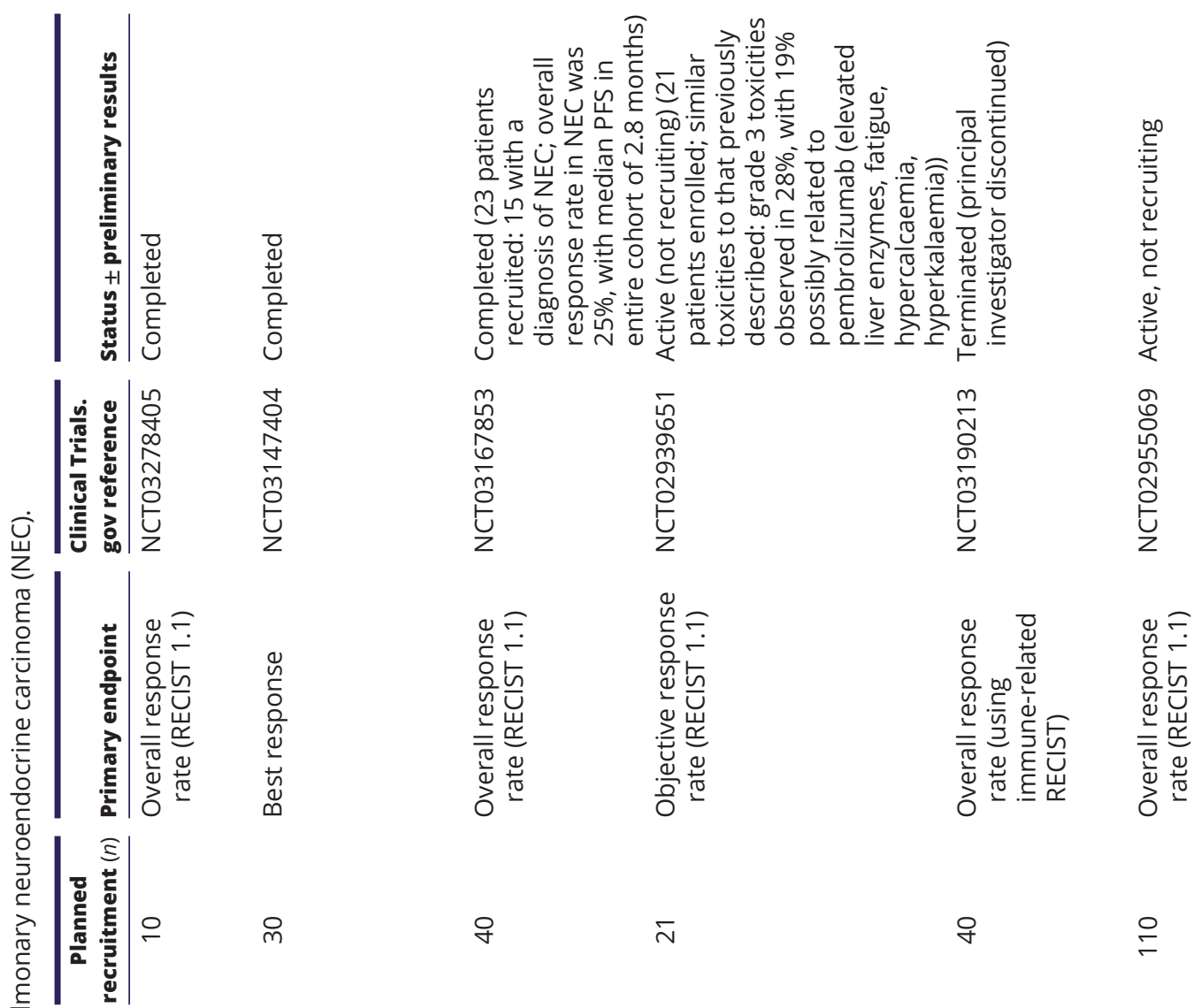
g
$\bar{\sim}$

q

$\stackrel{ }{ }$
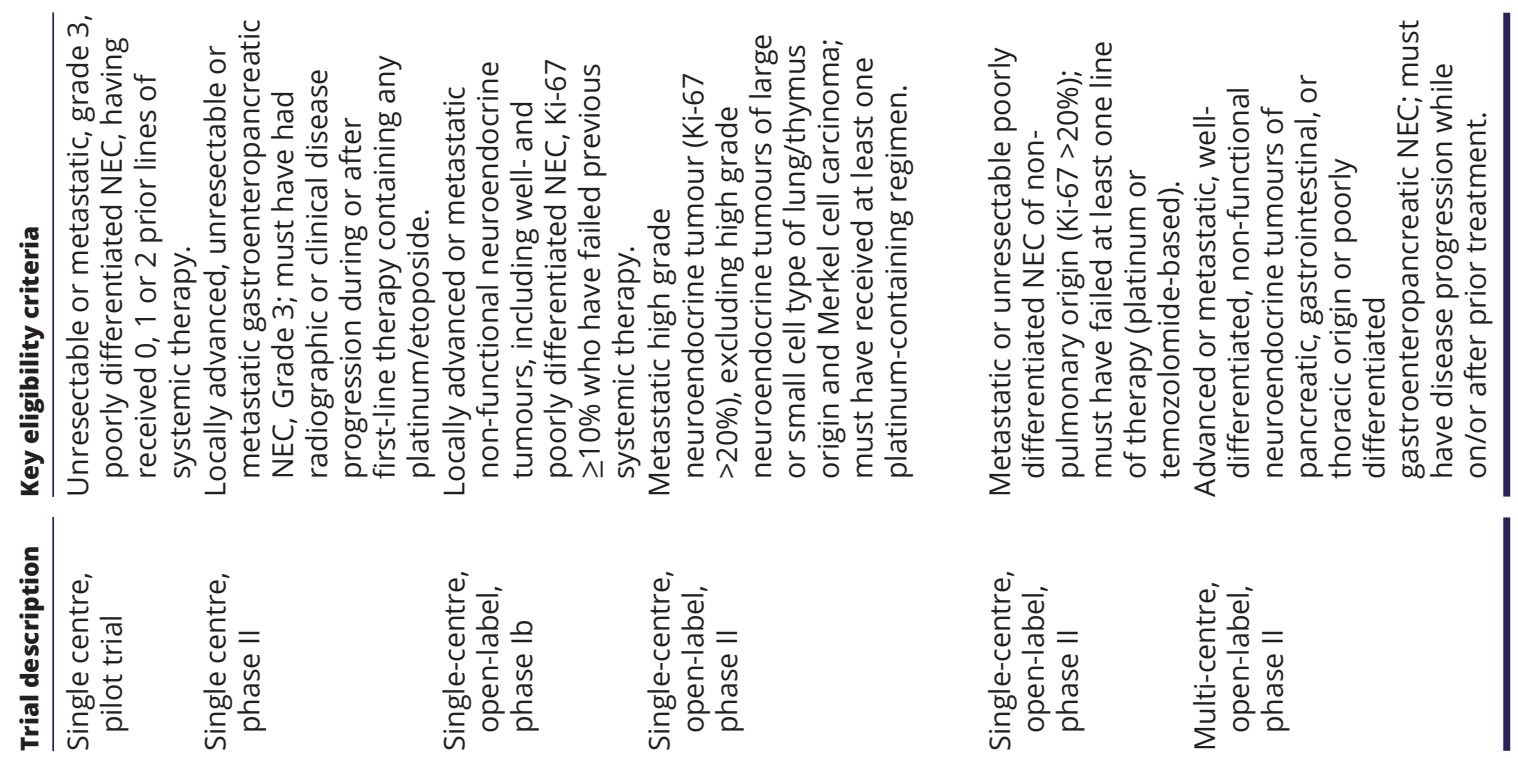

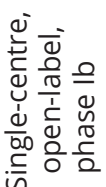

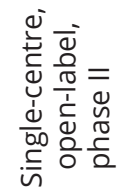

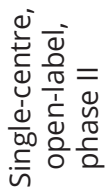
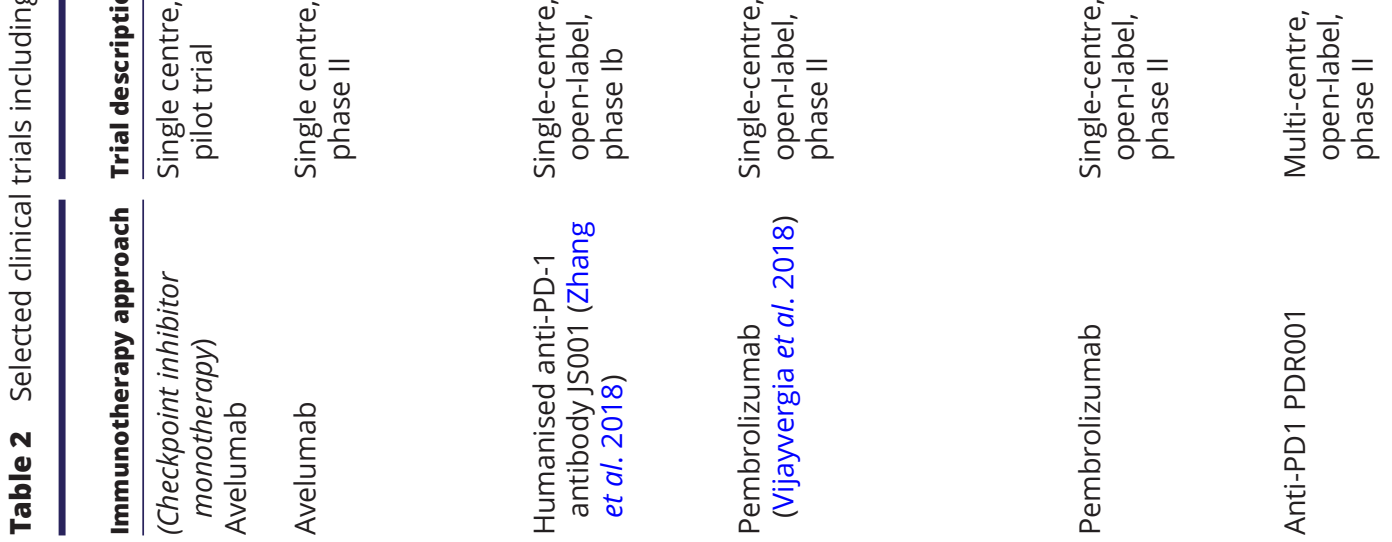

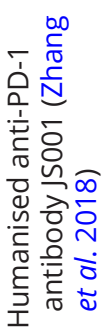

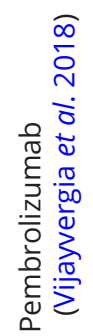

$\frac{0}{10}$
$\frac{1}{3}$
$\frac{.1}{0}$
$\frac{0}{0}$
है
0

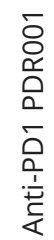



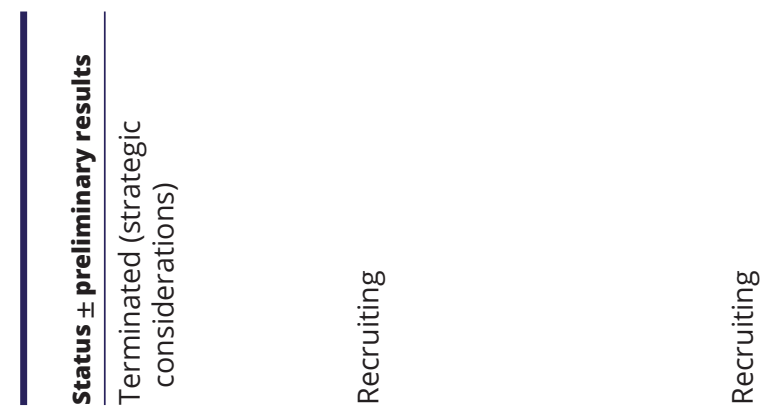

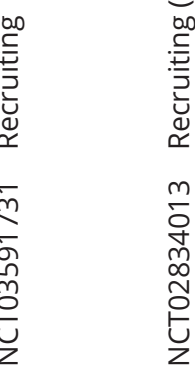
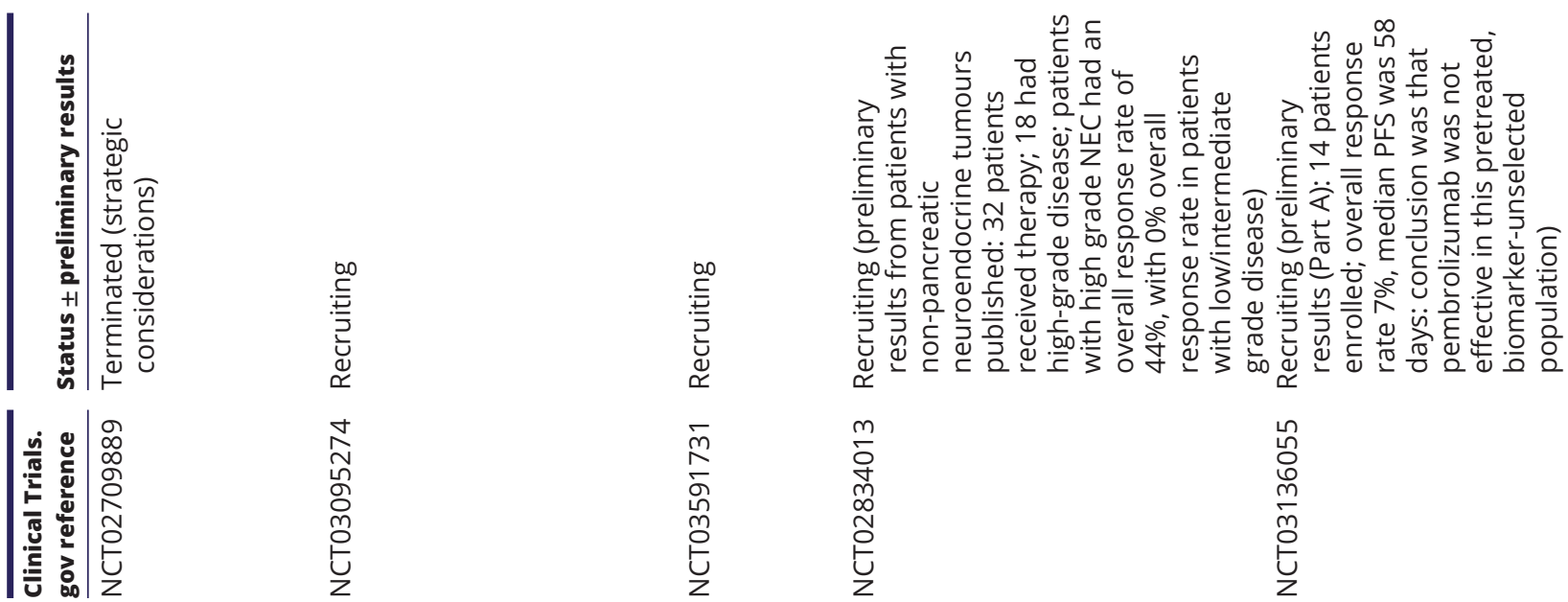

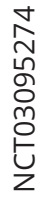

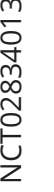

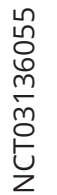
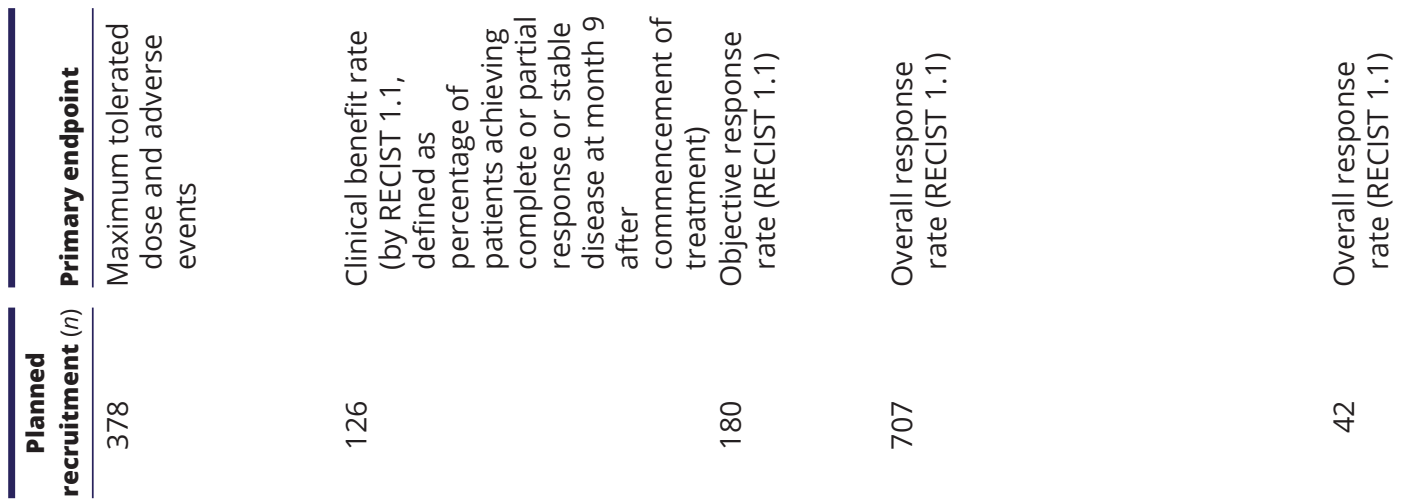

$\stackrel{\bullet}{\sim}$
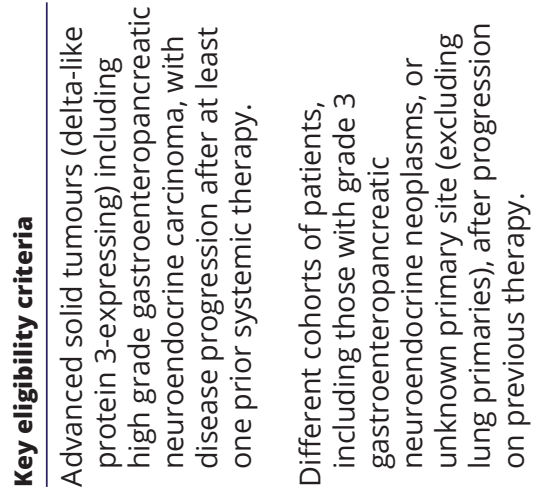

$\stackrel{\infty}{-}$

오

ชั
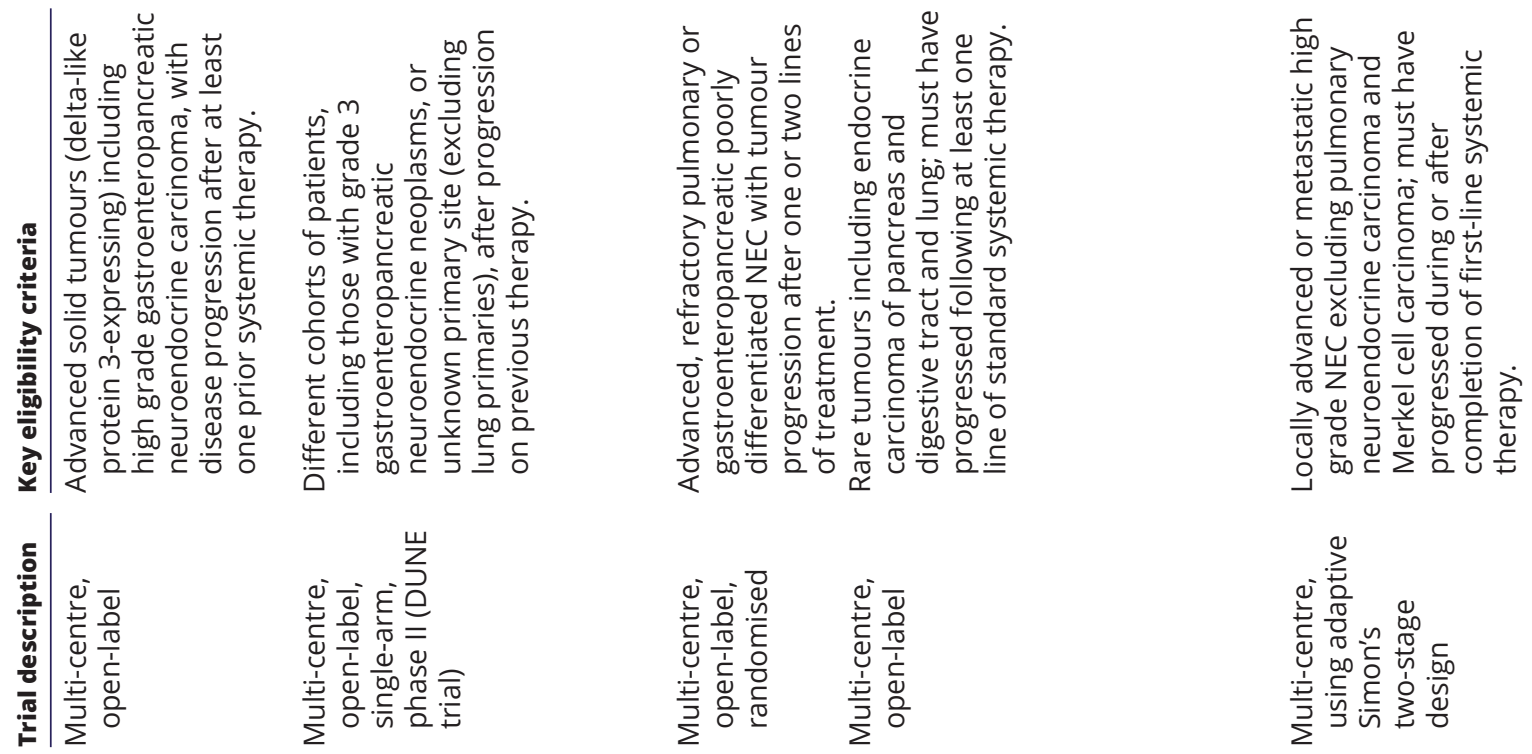

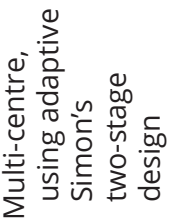

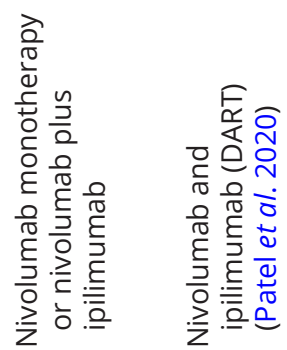




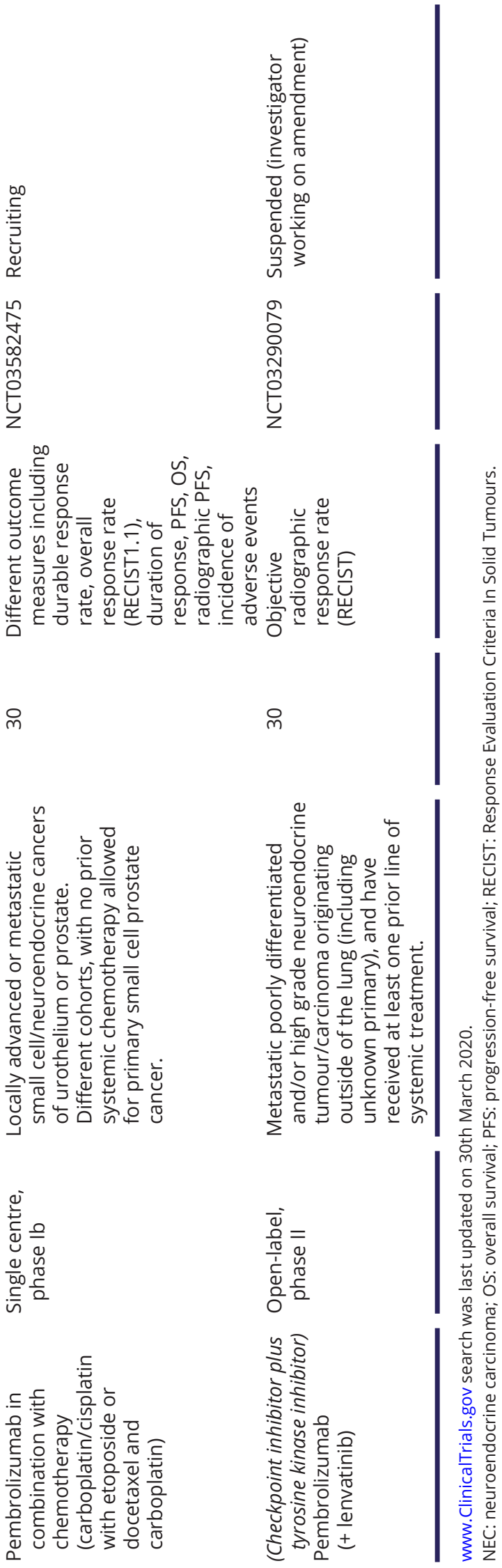

https://erc.bioscientifica.com https://doi.org/10.1530/ERC-19-0483
C) 2020 Society for Endocrinology Published by Bioscientifica Ltd. Printed in Great Britain
Microsatellite instability and high mutational load are more pronounced in high grade NENs (Sahnane et al. 2015), and to date, clinical experience of immune checkpoint blockade in NENs mainly exists for Merkel cell carcinoma (D'Angelo et al. 2018), and results of on-going immunotherapy trials in NEC with translational end-points will be informative (Table 2). There has been a case report of a patient with mismatch repair deficient platinum-resistant colorectal NEC, with a history of Lynch syndrome, who received pembrolizumab and subsequently underwent resection, with lack of radiologically evident metastatic disease 24 months after immunotherapy discontinuation (Whitman et al. 2019).

Despite the paucity of data published on the immune microenvironment of EP-NEC, there are a number of clinical trials investigating the use of immune-targeted agents in this disease category (Table 2). Emerging data from studies, thus far, have been conflicting. In preliminary analysis of a phase II study (NCT 02955069), the activity and safety of spartalizumab (PDR001), a highaffinity, humanised, anti-PD-1 IgG4 antibody that blocks PD-L1 and PD-L2 binding to PD-1, was assessed in 21 patients with GEP-NEC who had progressed on one line of chemotherapy; confirmed RR was 5\%, and the authors concluded that T-cell immunoglobulin and mucin-domain containing-3 (TIM3) expression in immune cells may be associated with the lack of response in patients with GEP NEC (Yao et al. 2018). In contrast, a non-randomised phase Ib trial (NCT 03167853) examined the efficacy and safety of PD-1 blockade with Toripalimab (JS001) in 28 patients with NEC who had failed standard treatment; the RR reported was $17.9 \%$ by Response Evaluation Criteria in Solid Tumours (RECIST) (Zhang et al. 2018), and it was concluded that patients with PD-L1 positive NENs might preferentially respond to JS001 treatment, but larger studies were recommended.

A phase II trial of the anti-PD-L1 antibody avelumab in 27 patients with advanced, metastatic high-grade NENs G3 (16 with G3 NEC and 11 with moderately differentiated G3 NETs) who had progressed after first-line chemotherapy (AVENEC) reported (interim analysis) that the disease control rate (stable disease or partial remission according to immune-related RECIST) after 8 weeks was $32 \%$, and in responders, the mean duration of disease control was 20 weeks, with four patients having stable disease or partial response $\geq 6$ months (with excellent tolerability) (Fottner et al. 2019).

Two studies have presented preliminary results of pembrolizumab monotherapy in previously treated patients with extrapulmonary poorly differentiated 
NEC (NCT 03136055 and NCT02939651); treatment was well tolerated, but initial results concluded that pembrolizumab in monotherapy was not effective in these biomarker-unselected populations of patients with EP-NEC (poorly differentiated), arising in different organs (Vijayvergia et al. 2018, Mulvey et al. 2019).

The results from the neuroendocrine cohort of the Southwest Oncology Group (SWOG) S1609 study, dual anti-cytotoxic T-lymphocyte-associated antigen 4 (CTLA-4) and anti-PD-1 blockade in rare tumours (DART) (NCT02834013), have recently been reported (Patel et al. 2020). This was a multi-centre phase II clinical trial of ipilimumab (1 $\mathrm{mg} / \mathrm{kg}$ every 6 weeks) plus nivolumab (240 mg intravenously every 2 weeks) across multiple cohorts of rare tumours. In the neuroendocrine cohort, 32 eligible patients received therapy; 58\% $(n=19)$ had high grade disease, with the most common sites being gastrointestinal (non-pancreatic) $(45 \% ; n=15)$ and lung $(18 \% ; n=16)$. The patients had received a median of two lines of prior therapy. The overall RR was 25\% and patients with NEC had a RR of $44 \%$. All patients who had a complete or partial response had high grade disease. The 6-month PFS reported was 31\% and the median OS was 11 months. It was hypothesised that NEC may have a higher tumour mutational burden, indicating a better response to immunotherapy, but this needs to be verified (MSI status was not readily available for the patients with non-pancreatic NETs enrolled in this study).

Recently, Li and colleagues have reported that combining immunotherapy with modified formulations of traditional cancer therapies, such as radiotherapy and chemotherapy, may stimulate an inflammatory response, eliciting a more effective response to immunotherapy, thereby turning immunologically 'cold' tumours (contain few infiltrating $\mathrm{T}$ cells and so are not recognised and do not provoke a strong response by the immune system) into 'hot' ones (Li et al. 2018). In EP-NEC, to date, the studies reported have not adopted this rationale, and this may potentially explain the predominantly less than favourable results.

Other options for combination with immunotherapy may include peptide receptor radionuclide therapy (PRRT) (Kong \& Hicks 2019). However, the use of PRRT in patients with grade 3 gastroenteropancreatic NETs is less well defined (Ezziddin et al. 2011). Sorbye et al. have advised that PRRT could be considered for patients with increased uptake on somatostatin receptor imaging, in patients with grade 3 gastroenteropancreatic NETs as well as in cases of NEC with a Ki-67 of $21-55 \%$ (Sorbye et al. 2020). Information on the combination of tyrosine kinase inhibitors with immunotherapy in patients with NEC is lacking and a phase 2 study of pembrolizumab with the multiple kinase inhibitor lenvatinib in previously treated patients with extra-pulmonary (including unknown primary) metastatic poorly differentiated and/or high grade NETs/carcinoma has been suspended (investigator working on amendment) (NCT03290079). There are no trials utilising chimeric antigen receptor (CAR) T-cell therapy recorded on clinicaltrials.gov enrolling patients specifically with a NEC diagnosis to date, and further research on NEC immune mechanisms is required prior to embarking on this treatment pathway.

\section{Future directions}

\section{The use of cell lines and patient-derived xenografts (PDX) to predict response to treatment in NEC}

Insights into the biology of NEC are crucial for identification of potential therapeutic molecular targets, and cell lines derived from tumour tissue may be helpful. Cell lines have been derived from liver (NEC-DUE1) or lymph node metastases (NEC-DUE2) from patients with large cell gastro-oesophageal junction and large intestine NECs, respectively (Krieg et al. 2014). Both cell lines retained malignant potential in vitro and in vivo. Resistance to chemotherapy such as cisplatin, etoposide and oxaliplatin were exhibited by NEC-DUE1 and -DUE2, but the NECDUE1 cell line was sensitive to 5-FU (Krieg et al. 2014).

Another study examined the antitumour effects of three chemotherapy agents, cisplatin, etoposide and irinotecan, and their combinations in three small cell GEPNEC cell lines: a pancreatic NEC (A99), an oesophageal NEC (TYUC-1) and a duodenal NEC (TCC-NECT-2) (Ohmoto et al. 2018). The oesophageal cell line was the most susceptible to all agents, whereas the pancreatic NEC cell line was refractory. These preclinical models indicated that cisplatin was a key agent in treatment of NEC and that the cisplatin/irinotecan combination may be a reasonable option, although efficacy was moderate (Ohmoto et al. 2018). Whether these tools can enable establishment of novel targeted therapies is unknown, given the differences in cell line sensitivity to chemotherapeutic agents reported.

Shinji et al. recently established a novel cell line (SS-2) derived from resection of an ascending colon tumour (Shinji et al. 2019). The SS-2 cell line maintained characteristic features of the resected tumour, which were also retained when implanted into the s.c. tissue of 
nude mice, and the authors concluded that these cells may add to the current knowledge of the biological behaviour of midgut NEC and thus may provide a novel therapeutic examination platform (Shinji et al. 2019).

Gastric NEC is rich in blood vessels and has highly malignant biological behaviour (Lin et al. 2019). In Lin et al., immunohistochemistry was used to assess expression of CDK5RAP3 in tumour tissue and adjacent non-tumour tissue from gastric NEC. Cell lines with stable overexpression or knockdown of CDK5RAP3 were developed using lentiviral transfection; protein levels of CDK5RAP3 were reduced in tissue from gastric NEC and low expression correlated with more advanced stage, increased tumour micro-vessel density and poor prognosis. The authors reported that CDK5RAP3 inhibited angiogenesis and thus could be a potential therapeutic target in gastric NEC (Lin et al. 2019).

Cell lines may exhibit significant genetic divergence compared to the primary tumour in patients with cancer. The establishment of a PDX model of NEC potentially will recapitulate the heterogeneity of the patient's primary tumour and possess more biological stability of gene expression and mutational status (Tentler et al. 2012). A human gastric NEC-derived xenograft model called GA0087 has been previously established, which demonstrates high gene expression of VEGF-A and $B$ and high potential for lung metastasis, and it was concluded by the authors that this may provide a robust platform for cancer research, as well as novel anti-cancer drug development (Jiang et al. 2015), but this awaits confirmation.

\section{The emergence of alternative biomarkers}

Development of new circulating biomarkers that can inform patient management and facilitate novel drug development are needed. In a single centre prospective study, Khan et al. concluded that circulating tumour cells (CTCs), enumerated using CellSearch (Veridex, Raritan, NJ, USA) were promising prognostic markers for patients with NENs (Khan et al. 2013). In total, 176 patients were recruited in this study (primary sites: midgut, pancreatic, bronchial and unknown), including 29 patients with G3-NENs (differentiation not reported, nor primary site of those with G3-NENs). Of those, $28 \%$ had $\geq 50$ CTCs and $66 \%$ had $\geq 1$ CTC. The presence of $\geq 1$ CTC was associated with worse PFS and OS, and on multivariable analysis, CTCs remained significant when the other prognostic markers, grade, tumour burden and chromogranin A, were included (Khan et al. 2013). In a follow-up study by the same authors, it was reported that changes in CTCs were associated with response to treatment and OS in metastatic NENs, suggesting that CTCs may be useful as surrogate markers to direct clinical decision making (Khan et al. 2016). One hundred and thirty-eight patients with metastatic NENs who were commencing therapy were prospectively recruited in this study; 26 patients had G3 NENs. The best prognostic group were those with 0 CTCs before and after therapy, followed by those with $\geq 50 \%$ reduction in CTCs (HR 3.31), and those with $<50 \%$ reduction, or increase in CTCs, had the worst outcome (HR 5.07) (Khan et al. 2016).

The role of miRNAs (small endogenous non-coding RNAs of 19-25 nucleotides in length that control eucaryotic gene expression post-transcriptionally through inhibition of degradation or translation of specific messenger RNAs (He \& Hannon 2004)) as prognostic markers in NENs is not well defined, and prospective studies are required to elucidate their prognostic ability (Zatelli et al. 2017).

Genomic subtyping using cell-free DNA (cfDNA) analysis has been successfully reported in 63 patients with pulmonary large-cell NEC and may have potential in prognostication and therapeutic decision making for these patients (Zhuo et al. 2020). To date, results using this technology have not been reported in EP-NEC. Tumourspecific genetic alterations in cfDNA of patients with metastatic pancreatic NETs have been reported (Boons et al. 2018) and results in EP-NEC are eagerly awaited.

\section{Conclusion}

There are many unanswered questions in relation to the most effective prognostic markers and treatment strategies for patients with EP-NEC, both localised and advanced. Eastern Cooperative Oncology Group PS, presence of liver metastases, haematological markers (platelets), biochemical markers such as ALK and LDH, histological markers such Ki-67 and Rb, CTCs and use of chemotherapy may have prognostic value (Khan et al. 2013, 2016, Sorbye et al. 2013, Lamarca et al. 2017, Alese et al. 2019).

Preliminary data have reported that the median survival in patients with advanced disease receiving platinum-based chemotherapy up-front is better in patients with small cell lung cancer than in EP-NEC (Terashima et al. 2012). A lower rate of alterations in TP53 and $R B 1$ were reported in EP-NECs, when compared to small cell lung cancer, and so optimal therapy for EP-NECs may be site specific and different from small cell lung 
cancer (Bergsland et al. 2016). A better understanding of the underlying biology of EP-NEC is critical. Better models of this diagnosis are vital, and human NECderived xenograft models may provide a unique platform for cancer research, as well as for pre-clinical evaluation of therapeutic efficacy of novel anti-cancer agents. Additionally, there are limited pre-clinical data published on the immune microenvironment of EP-NEC, and further research in this area is necessary.

Whether differential treatment strategies are required for small cell and large cell NECs is uncertain, as is the necessity for individualised primary tumour site therapy, with potential molecular stratification. Collaborative prospective trials with translational correlates are warranted and may inform future biomarker-driven studies.

\section{Declaration of interest}

The authors declare that there is no conflict of interest that could be perceived as prejudicing the impartiality of this review.

\section{Funding}

This work did not receive any specific grant from any funding agency in the public, commercial or not-for-profit sector.

\section{Author contribution statement}

M G McNamara developed the review concept and drafted the manuscript. All authors were involved in design, critical revision and approval of the manuscript.

\section{References}

Alese OB, Jiang R, Shaib W, Wu C, Akce M, Bejera M \& El-Rayes BF 2019 High-grade gastrointestinal neuroendocrine carcinoma management and outcomes: a National Cancer Database study. Oncologist 24 911-920. (https://doi.org/10.1634/theoncologist.2018-0382).

Ali AS, Gronberg M, Federspiel B, Scoazec JY, Hjortland GO, Gronbaek H, Ladekarl M, Langer SW, Welin S, Vestermark LW, et al. 2017 Expression of p53 protein in high-grade gastroenteropancreatic neuroendocrine carcinoma. PLoS ONE 12 e0187667. (https://doi. org/10.1371/journal.pone.0187667)

Ali AS, Gronberg M, Langer SW, Ladekarl M, Hjortland GO, Vestermark LW, Österlund P, Welin S, Grønbæk H, Knigge U, et al. 2018 Intravenous versus oral etoposide: efficacy and correlation to clinical outcome in patients with high-grade metastatic gastroenteropancreatic neuroendocrine neoplasms (WHO G3). Medical Oncology 35 47. (https://doi.org/10.1007/s12032-018-1103-x)

Alitalo K, Schwab M, Lin CC, Varmus HE \& Bishop JM 1983 Homogeneously staining chromosomal regions contain amplified copies of an abundantly expressed cellular oncogene (c-myc) in malignant neuroendocrine cells from a human colon carcinoma. PNAS 80 1707-1711. (https://doi.org/10.1073/pnas.80.6.1707)
Arnold CN, Nagasaka T, Goel A, Scharf I, Grabowski P, Sosnowski A, Schmitt-Gräff A, Boland CR, Arnold R \& Blum HE 2008 Molecular characteristics and predictors of survival in patients with malignant neuroendocrine tumors. International Journal of Cancer $\mathbf{1 2 3}$ 1556-1564. (https://doi.org/10.1002/ijc.23690)

Basturk O, Tang L, Hruban RH, Adsay V, Yang Z, Krasinskas AM, Vakiani E, La Rosa S, Jang KT, Frankel WL, et al. 2014 Poorly differentiated neuroendocrine carcinomas of the pancreas: a clinicopathologic analysis of 44 cases. American Journal of Surgical Pathology 38 437-447. (https://doi.org/10.1097/ PAS.0000000000000169)

Bergsland EK, Roy R, Stephens P, Ross JS, Bailey M \& Olshen A 2016 Genomic profiling to distinguish poorly differentiated neuroendocrine carcinomas arising in different sites. Journal of Clinical Oncology 34 (Supplement 15) 4020-4020. (https://doi. org/10.1200/JCO.2016.34.15_suppl.4020)

Boons G, Vandamme T, Peeters M, Beyens M, Driessen A, Janssens K, Zwaenepoel K, Roeyen G, Van Camp G \& Op de Beeck K 2018 Cellfree DNA from metastatic pancreatic neuroendocrine tumor patients contains tumor-specific mutations and copy number variations. Frontiers in Oncology 8 467. (https://doi.org/10.3389/ fonc.2018.00467)

Bosman FT, Carneiro F, Hruban RH \& Theise ND 2010 WHO Classification of Tumors of the Digestive System, 4th ed. Lyon, France: IARC Press.

Bouzbouz A, Abdulhakeem B, Laababsi R, Rouadi S, Abada R, Roubal M \& Mahtar M 2020 Rare cases of head and neck's neuroendocrine carcinomas disease: case series of 4 patients and review of the literature. International Journal of Surgery Case Reports 66 270-276. (https://doi.org/10.1016/j.ijscr.2019.12.003)

Brenner B, Tang LH, Klimstra DS \& Kelsen DP 2004 Small-cell carcinomas of the gastrointestinal tract: a review. Journal of Clinical Oncology 22 2730-2739. (https://doi.org/10.1200/JCO.2004.09.075)

Brenner B, Tang LH, Shia J, Klimstra DS \& Kelsen DP 2007 Small cell carcinomas of the gastrointestinal tract: clinicopathological features and treatment approach. Seminars in Oncology 34 43-50. (https://doi. org/10.1053/j.seminoncol.2006.10.022)

Busico A, Maisonneuve P, Prinzi N, Pusceddu S, Centonze G, Garzone G, Pelligrinelli A, Giacomelli L, Mangogna A, Paolino C, et al. 2019 Gastroenteropancreatic high-grade neuroendocrine neoplasms (H-NENs): histology and molecular analysis, two sides of the same coin. Neuroendocrinology [epub]. (https://doi.org/10.1159/000503722)

Capdevila J, Arqués O, Hernandez Mora JR, Matiti J, Caratu G, Mancuso FM, Landolfi S, Barriuso J, Jimenez-Fonseca P, Lopez Lopez C, et al. 2020 Epigenetic EGFR gene repression confers sensitivity to therapeutic BRAFV600E blockade in colon neuroendocrine carcinomas. Clinical Cancer Research 26 902-909. (https://doi.org/10.1158/1078-0432.CCR-19-1266)

Casas F, Ferrer F, Farrus B, Casals J \& Biete A 1997 Primary small cell carcinoma of the oesophagus: a review of the literature with emphasis on therapy and prognosis. Cancer 80 1366-1372. (https:// doi.org/10.1002/(SICI)1097-0142(19971015)80:8<1366::AIDCNCR2>3.0.CO;2-D)

Chang MT, Penson A, Desai NB, Socci ND, Shen R, Seshan VE, Kundra R, Abeshouse A, Viale A, Cha EK, et al. 2018 Small cell carcinomas of the bladder and lung are characterized by a convergent but distinct pathogenesis. Clinical Cancer Research $\mathbf{2 4}$ 1965-1973. (https://doi.org/10.1158/1078-0432.CCR-17-2655)

Cho SY, Choi M, Ban HJ, Lee CH, Park S, Kim H, Kim YS, Lee YS \& Lee JY 2017 Cervical small cell neuroendocrine tumor mutation profiles via whole exome sequencing. Oncotarget 8 8095-8104. (https://doi.org/10.18632/oncotarget.14098)

Craig Z, Swain J, Batman E, Wadsley J, Reed N, Faluyi O, Cave J, Sharma R, Chau I, Wall L, et al. 2020 NET-02 trial protocol: a multicentre, randomised, parallel group, open-label, phase II, singlestage selection trial of liposomal irinotecan (nal-IRI) and (c) 2020 Society for Endocrinology Published by Bioscientifica Ltd. Printed in Great Britain 
5-fluorouracil (5-FU)/folinic acid or docetaxel as second-line therapy in patients with progressive poorly differentiated extrapulmonary neuroendocrine carcinoma (NEC). BMJ Open 10 e034527. (https:// doi.org/10.1136/bmjopen-2019-034527)

D'Angelo SP, Russell J, Lebbe C, Chmielowski B, Gambichler T, Grob JJ, Kiecker F, Rabinowits G, Terheyden P, Zwiener I, et al. 2018 Efficacy and safety of first-line avelumab treatment in patients with stage IV metastatic Merkel cell carcinoma. A preplanned interim analysis of a clinical trial. JAMA Oncology 4 e180077. (https://doi.org/10.1001/ jamaoncol.2018.0077)

Dasari A, Mehta K, Byers LA, Sorbye H \& Yao JC 2018 Comparative study of lung and extrapulmonary poorly differentiated neuroendocrine carcinomas: a SEER database analysis of 162,983 cases. Cancer 124 807-815. (https://doi.org/10.1002/cncr.31124)

Derks JL, Leblay N, Thunnissen E, van Suylen RJ, den Bakker M, Groen HJM, Smit EF, Damhuis R, van den Broek EC, Charbrier A, et al. 2018 Molecular subtypes of pulmonary large-cell neuroendocrine carcinoma predict chemotherapy treatment outcome. Clinical Cancer Research 24 33-42. (https://doi. org/10.1158/1078-0432.CCR-17-1921)

Ezziddin S, Opitz M, Attassi M, Biermann K, Sabet A, Guhlke S, Brockmann H, Willinek W, Wardelmann E, Biersack HJ, et al. 2011 Impact of the Ki-67 proliferation index on response to peptide receptor radionuclide therapy. European Journal of Nuclear Medicine and Molecular Imaging 38 459-466. (https://doi.org/10.1007/s00259010-1610-2)

Fottner C, Apostolidis L, Ferrata M, Krug S, Michl P, Schad A, Roth W, Jaeger D, Galle PR \& Weberet MM 2019 A phase II, open label, multicentre trial of avelumab in patients with advanced, metastatic high-grade neuroendocrine carcinomas NEC G3 (WHO 2010) progressive after first-line chemotherapy (AVENEC). Journal of Clinical Oncology 37 (Supplement 15) abstr 4103. (https://doi. org/10.1200/JCO.2019.37.15_suppl.4103)

Freis P, Graillot E, Rousset P, Hervieu V, Chardon L, Lombard-Bohas C \& Walter T 2017 Prognostic factors in neuroendocrine carcinoma: biological markers are more useful than histomorphological markers. Scientific Reports 7 40609. (https://doi.org/10.1038/srep40609)

Frizziero M, Spada F, Lamarca A, Kordatou Z, Barriuso J, Nuttall C, McNamara MG, Hubner RA, Mansoor W, Manoharan P, et al. 2019 Carboplatin in combination with oral or intravenous etoposide for extra-pulmonary, poorly-differentiated neuroendocrine carcinomas. Neuroendocrinology 109 100-112. (https://doi.org/10.1159/000497336)

Frizziero M, Chakrabarty B, Nagy B, Lamarca A, Hubner RA, Valle JW \& McNamara MG 2020 Mixed neuroendocrine non-neuroendocrine neoplasms: a systematic review of a controversial and underestimated diagnosis. Journal of Clinical Medicine 9 E273. (https://doi.org/10.3390/jcm9010273)

Frumovitz M, Burzawa JK, Byers LA, Lyons YA, Ramalingam P, Coleman RL \& Brown J 2016 Sequencing of mutational hotspots in cancer-related genes in small cell neuroendocrine cervical cancer. Gynecologic Oncology 141 588-591. (https://doi.org/10.1016/j. ygyno.2016.04.001)

Gandini S, Massi D \& Mandala M 2016 PD-L1 expression in cancer patients receiving anti PD-1/PD-L1 antibodies: a systematic review and meta-analysis. Critical Reviews in Oncology/Hematology 100 88-98. (https://doi.org/10.1016/j.critrevonc.2016.02.001)

Garcia-Carbonero R, Sorbye H, Baudin E, Raymond E, Wiedenmann B, Niederle B, Sedlackova E, Toumpanakis C, Anlauf M, Cwikla JB, et al. 2016 Enets consensus guidelines for high-grade gastroenteropancreatic neuroendocrine tumours and neuroendocrine carcinomas. Neuroendocrinology 103 186-194. (https://doi. org/10.1159/000443172)

George J, Lim JS, Jang SJ, Cun Y, Ozretic L, Kong G, Leenders F, Lu X, Fernández-Cuesta L, Bosco G, et al. 2015 Comprehensive genomic profiles of small cell lung cancer. Nature $\mathbf{5 2 4} 47-53$. (https://doi. org/10.1038/nature14664)
George J, Walter V, Peifer M, Alexandrov LB, Seidel D, Leenders F, Maas L, Müller C, Dahmen I, Delhomme TM, et al. 2018 Integrative genomic profiling of large-cell neuroendocrine carcinomas reveals distinct subtypes of high-grade neuroendocrine lung tumors. Nature Communications 9 1048. (https://doi.org/10.1038/s41467-01803099-x)

Girardi DM, Silva ACB, Rego JFM, Coudry RA \& Riechelmann RP 2017 Unraveling molecular pathways of poorly differentiated neuroendocrine carcinomas of the gastroenteropancreatic system: a systematic review. Cancer Treatment Reviews 56 28-35. (https://doi. org/10.1016/j.ctrv.2017.04.002)

Goyal B, Duncavage EJ, Martinez D, Lewis Jr JS \& Chernock RD 2014 Next-generation sequencing of salivary high-grade neuroendocrine carcinomas identifies alterations in RB1 and the mTOR pathway. Experimental and Molecular Pathology 97 572-578. (https://doi. org/10.1016/j.yexmp.2014.10.011)

Gupta S, Sahu D, Bomalaski JS, Frank I, Boorjian SA, Thapa P, Cheville JC \& Hansel DE 2018 Argininosuccinate synthetase-1 (ASS1) loss in high-grade neuroendocrine carcinomas of the urinary bladder: implications for targeted therapy with ADI-PEG 20. Endocrine Pathology 29 236-241. (https://doi.org/10.1007/s12022-0189516-9)

Hadoux J, Malka D, Planchard D, Scoazec JY, Caramella C, Guigay J, Boige V, Leboulleux S, Burtin P, Berdelou A, et al. 2015 Post-first-line FOLFOX chemotherapy for grade 3 neuroendocrine carcinoma. Endocrine-Related Cancer 22 289-298. (https://doi.org/10.1530/ERC15-0075)

Hammond WA, Crozier JA, Nakhleh RE \& Mody K 2016 Genomic profiling of high-grade large-cell neuroendocrine carcinoma of the colon. Journal of Gastrointestinal Oncology 7 E22-E24. (https://doi. org/10.3978/j.issn.2078-6891.2015.090)

He L \& Hannon GJ 2004 MicroRNAs: small RNAs with a big role in gene regulation. Nature Reviews: Genetics 5 522-531. (https://doi. org/10.1038/nrg1379)

Hentic O, Hammel P, Couvelard A, Rebours V, Zappa M, Palazzo M, Maire F, Goujon G, Gillet A, Lévy P, et al. 2012 FOLFIRI regimen: an effective second-line chemotherapy after failure of etoposideplatinum combination in patients with neuroendocrine carcinomas grade 3. Endocrine-Related Cancer 19 751-757. (https://doi. org/10.1530/ERC-12-0002)

Hijioka S, Hosoda W, Matsuo K, Ueno M, Furukawa M, Yoshitomi H, Kobayashi N, Ikeda M, Ito T, Nakamori S, et al. 2017 Rb loss and KRAS mutation are predictors of the response to platinum-based chemotherapy in pancreatic neuroendocrine neoplasm with grade 3 : a Japanese multicenter pancreatic NEN-G3 study. Clinical Cancer Research 23 4625-4632. (https://doi.org/10.1158/1078-0432.CCR-163135)

Idrees K, Padmanabhan C, Liu E, Guo Y, Gonzalez RS, Berlin J, Dahlman KB, Beauchamp RD \& Shi C 2018 Frequent BRAF mutations suggest a novel oncogenic driver in colonic neuroendocrine carcinoma. Journal of Surgical Oncology 117 284-289. (https://doi.org/10.1002/jso.24834)

Janson ET, Sorbye H, Welin S, Federspiel B, Gronbaek H, Hellman P, Mathisen O, Mortensen J, Sundin A, Thiis-Evensen E, et al. 2010 Nordic Guidelines 2010 for diagnosis and treatment of gastroenteropancreatic neuroendocrine tumours. Acta Oncologica 49 740-756. (https://doi.org/10.3109/0284186X.2010.492791)

Jesinghaus M, Konukiewitz B, Keller G, Kloor M, Steiger K, Reiche M, Penzel R, Endris V, Arsenic R, Hermann G, et al. 2017 Colorectal mixed adenoneuroendocrine carcinomas and neuroendocrine carcinomas are genetically closely related to colorectal adenocarcinomas. Modern Pathology 30 610-619. (https://doi. org/10.1038/modpathol.2016.220)

Jiang J, Wang DD, Yang M, Chen D, Pang L, Guo S, Cai J, Wery JP, Li L, Li HQ, et al. 2015 Comprehensive characterization of chemotherapeutic efficacy on metastases in the established gastric (c) 2020 Society for Endocrinology Published by Bioscientifica Ltd. Printed in Great Britain 
neuroendocrine cancer patient derived xenograft model. Oncotarget 6 15639-15651. (https://doi.org/10.18632/oncotarget.3712)

Karkouche R, Bachet JB, Sandrini J, Mitry E, Penna C, Cote JF, Blons H, Penault-Llorca F, Rougier P, Saint André JP, et al. 2012 Colorectal neuroendocrine carcinomas and adenocarcinomas share oncogenic pathways. A clinico-pathologic study of 12 cases. European Journal of Gastroenterology and Hepatology 24 1430-1437. (https://doi. org/10.1097/MEG.0b013e3283583c87)

Khan MS, Kirkwood A, Tsigani T, Garcia-Hernandez J, Hartley JA, Caplin ME \& Meyer T 2013 Circulating tumor cells as prognostic markers in neuroendocrine tumors. Journal of Clinical Oncology 31 365-372. (https://doi.org/10.1200/JCO.2012.44.2905)

Khan MS, Kirkwood AA, Tsigani T, Lowe H, Goldstein R, Hartley JA, Caplin ME \& Meyer T 2016 Early changes in circulating tumor cells are associated with response and survival following treatment of metastatic neuroendocrine neoplasms. Clinical Cancer Research 22 79-85. (https://doi.org/10.1158/1078-0432.CCR-15-1008)

Kimura T, Miyamoto H, Fukuya A, Kitamura S, Okamoto K, Kimura M, Muguruma N, Ikemoto T, Shimada M, Yoneda A, et al. 2016 Neuroendocrine carcinoma of the pancreas with similar genetic alterations to invasive ductal adenocarcinoma. Clinical Journal of Gastroenterology 9 261-265. (https://doi.org/10.1007/s12328-0160655-6)

Klempner SJ, Gershenhorn B, Tran P, Lee TK, Erlander MG, Gowen K, Schrock AB, Morosini D, Ross JS, Miller VA, et al. 2016 BRAFV600E mutations in high-grade colorectal neuroendocrine tumors may predict responsiveness to BRAF-MEK combination therapy. Cancer Discovery 6 594-600. (https://doi.org/10.1158/2159-8290.CD-151192)

Klöppel G 2017 Neuroendocrine neoplasms: dichotomy, origin and classifications. Visceral Medicine 33 324-330. (https://doi. org/10.1159/000481390)

Kong G \& Hicks RJ 2019 Peptide receptor radiotherapy: current approaches and future directions. Current Treatment Options in Oncology 20 77. (https://doi.org/10.1007/s11864-019-0677-7)

Konukiewitz B, Schlitter AM, Jesinghaus M, Pfister D, Steiger K, Segler A, Agaimy A, Sipos B, Zamboni G, Weichert W, et al. 2017 Somatostatin receptor expression related to TP53 and RB1 alterations in pancreatic and extrapancreatic neuroendocrine neoplasms with a Ki67-index above 20. Modern Pathology 30 587-598. (https://doi.org/10.1038/ modpathol.2016.217)

Konukiewitz B, Jesinghaus M, Steiger K, Schlitter AM, Kasajima A, Sipos B, Zamboni G, Weichert W, Pfarr N \& Klöppel G 2018 Pancreatic neuroendocrine carcinomas reveal a closer relationship to ductal adenocarcinomas than to neuroendocrine tumors G3. Human Pathology 77 70-79. (https://doi.org/10.1016/j.humpath.2018.03.018)

Krieg A, Mersch S, Boeck I, Dizdar L, Weihe E, Hilal Z, Krausch M, Möhlendick B, Topp SA, Piekorz RP, et al. 2014 New model for gastroenteropancreatic large-cell neuroendocrine carcinoma: establishment of two clinically relevant cell lines. PLOS ONE 9 e88713. (https://doi.org/10.1371/journal.pone.0088713)

Lamarca A, Walter T, Pavel M, Borbath I, Freis P, Nunez B, Childs A, McNamara MG, Hubner RA, Garcia-Carbonero R, et al. 2017 Design and validation of the GI-NEC score to prognosticate overall survival in patients with high-grade gastrointestinal neuroendocrine carcinomas. Journal of National Cancer Institute 109 djw2. (https:// doi.org/10.1093/jnci/djw277)

Lawrence B, Gustafsson BI, Chan A, Svejda B, Kidd M \& Modlin IM 2011 The epidemiology of gastroenteropancreatic neuroendocrine tumors. Endocrinology and Metabolism Clinics of North America $\mathbf{4 0}$ 1-18, vii. (https://doi.org/10.1016/j.ecl.2010.12.005)

Li J, Byrne KT, Yan F, Yamazoe T, Chen Z, Baslan T, Richman LP, Lin JH, Sun YH, Rech AJ, et al. 2018 Tumor cell-intrinsic factors underlie heterogeneity of immune cell infiltration and response to immunotherapy. Immunity 49 178.e7-193.e7. (https://doi. org/10.1016/j.immuni.2018.06.006)
Lin JX, Weng XF, Xie XS, Lian NZ, Qiu SL, Wang JB, Lu J, Chen QY, Cao LL, Lin M, et al. 2019 CDK5RAP3 inhibits angiogenesis in gastric neuroendocrine carcinoma by modulating AKT/HIF-1a/VEGFA signalling. Cancer Cell International 19 282. (https://doi.org/10.1186/ s12935-019-0997-5)

Lloyd RV, Osamura RY, Klöppel G \& Rosai J 2017 WHO Classification of Tumours of Endocrine Organs, 4th ed., pp. 209-240. Lyon, France: IARC Press.

McNamara MG, Frizziero M, Jacobs T, Lamarca A, Hubner RA, Valle J \& Amir E 2019 Second-line treatment in patients (pts) with advanced extra-pulmonary poorly differentiated neuroendocrine carcinoma (EP-PD-NEC): a systematic review and meta-analysis. Neuroendocrinology 108 (Supplement 1) 1-273.

Mishima S, Kawazoe A, Matsumoto H, Kuboki Y, Bando H, Kojima T, Doi T, Ohtsu A, Yoshino T, Nonte EM, et al. 2018 Efficacy and safety of ramucirumab-containing chemotherapy in patients with pretreated metastatic gastric neuroendocrine carcinoma. ESMO Open 3 e000443. (https://doi.org/10.1136/esmoopen-2018-000443)

Moertel CG, Kvols LK, O'Connell MJ \& Rubin J 1991 Treatment of neuroendocrine carcinomas with combined etoposide and cisplatin: evidence of major therapeutic activity in the anaplastic variants of these neoplasms. Cancer 68 227-232. (https://doi.org/10.1002/10970142(19910715)68:2<227::aid-cncr2820680202>3.0.co;2-i)

Morgan S, Slodkowska E, Parra-Herran C \& Mirkovic J 2019 PD-L1, RB1 and mismatch repair protein immunohistochemical expression in neuroendocrine carcinoma, small cell type, of the uterine cervix. Histopathology 74 997-1004. (https://doi.org/10.1111/his.13825)

Mulvey C, Raj NP, Chan JA, Aggarwal RR, Cinar P, Hope TA, Kolli K, Zhang L, Calabrese S, Grabowsky JA, et al. 2019 Phase II study of pembrolizumab-based therapy in previously treated extrapulmonary poorly differentiated neuroendocrine carcinomas: results of part A (pembrolizumab alone). Journal of Clinical Oncology 37 (Supplement 4) 363. (https://doi.org/10.1200/JCO.2019.37.4_suppl.363)

Nagtegaal ID, Odze RD, Klimstra D, Paradis V, Rugge M, Schirmacher P, Washington KM, Carneiro F, Cree IA \& WHO Classification of Tumours Editorial Board 2020 The 2019 WHO classification of tumours of the digestive system. Histopathology 76 182-188. (https:// doi.org/10.1111/his.13975)

Ohmoto A, Suzuke M, Takai E, Rokutan H, Fujiwara Y, Morizane C, Yanagihara K, Shibata T \& Yachida S 2018 Establishment of preclinical chemotherapy models for gastroenteropancreatic neuroendocrine carcinoma. Oncotarget 9 21086-21099. (https://doi. org/10.18632/oncotarget.24930)

Olevian DC, Nikiforova MN, Chiosea S, Sun W, Bahary N, Kuan SF \& Pai RK 2016 Colorectal poorly differentiated neuroendocrine carcinomas frequently exhibit BRAF mutations and are associated with poor overall survival. Human Pathology 49 124-134. (https:// doi.org/10.1016/j.humpath.2015.11.004)

Olsen IH, Sorensen JB, Federspiel B, Kjaer A, Hansen CP, Knigge U \& Langer SW 2012 Temozolomide as second or third line treatment of patients with neuroendocrine carcinomas. Scientific World Journal 2012 170496. (https://doi.org/10.1100/2012/170496)

Olsen IH, Knigge U, Federspiel B, Hansen CP, Skov A, Kjaer A \& Langer SW 2014 Topotecan monotherapy in heavily pretreated patients with progressive advanced stage neuroendocrine carcinomas. Journal of Cancer 5 628-632. (https://doi.org/10.7150/ jca.9409)

Patel SP, Othus M, Chae YK, Giles FJ, Hansel DE, Singh PP, Fontaine A, Shah MH, Kasi A, Al Baghdadi TA, et al. 2020 A phase II basket trial of dual anti-CTLA-4 and anti-PD-1 blockade in rare tumors (Dart SWOG 1609) in patients with non-pancreatic neuroendocrine tumors. Clinical Cancer Research 26 2290-2296. (https://doi. org/10.1158/1078-0432.CCR-19-3356)

Peifer M, Fernandez-Cuesta L, Sos ML, George J, Seidel D, Kasper LH, Plenker D, Leenders F, Sun R, Zander T, et al. 2012 Integrative genome analyses identify key somatic driver mutations of small-cell https://erc.bioscientifica.com

https://doi.org/10.1530/ERC-19-0483 (c) 2020 Society for Endocrinology Published by Bioscientifica Ltd. Printed in Great Britain 
lung cancer. Nature Genetics 44 1104-1110. (https://doi.org/10.1038/ ng.2396)

Rekhtman N, Pietanza MC, Hellmann MD, Naidoo J, Arora A, Won H, Halpenny DF, Wang H, Tian SK, Litvak AM, et al. 2016 Nextgeneration sequencing of pulmonary large cell neuroendocrine carcinoma reveals small cell carcinoma-like and non-small cell carcinoma-like subsets. Clinical Cancer Research 22 3618-3629. (https://doi.org/10.1158/1078-0432.CCR-15-2946)

Rickman DS, Beltran H, Demichelis F \& Rubin MA 2017 Biology and evolution of poorly differentiated neuroendocrine tumors. Nature Medicine 23 1-10. (https://doi.org/10.1038/nm.4341)

Rindi G, Klimstra DS, Abedi-Ardekani B, Asa SL, Bosman FT, Brambilla E, Busam KJ, de Krijger RR, Dietel M, El-Naggar AK, et al. 2018a A common classification framework for neuroendocrine neoplasms: an International Agency for Research on Cancer (IARC) and World Health Organization (WHO) expert consensus proposal. Modern Pathology 31 1770-1786. (https://doi.org/10.1038/s41379-0180110-y)

Rindi G, Klersy C, Albarello L, Baudin E, Bianchi A, Buchler MW, Caplin M, Couvelard A, Cros J, de Herder WW, et al. $2018 b$ Competitive testing of the WHO 2010 vs the 2017 grading of pancreas neuroendocrine neoplasia: data from a large international cohort study. Neuroendocrinology 107 375-386. (https://doi. org/10.1159/000494355)

Roininen N, Takala S, Haapasaari KM, Jukkola-Vuorinen A, Mattson J, Heikkila P \& Karihtala P 2019 Neuroendocrine breast carcinomas share prognostic factors with gastroenteropancreatic neuroendocrine tumors: a putative prognostic role of menin, p27, and SSTR-2A. Oncology 96 147-155. (https://doi.org/10.1159/000493348)

Rossi A, DiMaio M, Chiodini P, Rudd RM, Okamoto H, Skarlos DV, Früh M, Qian W, Tamura T, Samantas E, et al. 2012 Carboplatin- or cisplatin-based chemotherapy in first-line treatment of small-cell lung cancer: the COCIS meta-analysis of individual patient data. Journal of Clinical Oncology 30 1692-1698. (https://doi.org/10.1200/ JCO.2011.40.4905)

Rudin CM, Durinck S, Stawiski EW, Poirier JT, Modrusan Z, Shames DS, Bergbower EA, Guan Y, Shin J, Guillory J, et al. 2012 Comprehensive genomic analysis identifies SOX2 as a frequently amplified gene in small-cell lung cancer. Nature Genetics 44 1111-1116. (https://doi. org/10.1038/ng.2405)

Sahnane N, Furlan D, Monti M, Romualdi C, Vanoli A, Vicari E, Solcia E, Capella C, Sessa F \& La Rosa S 2015 Microsatellite unstable gastrointestinal neuroendocrine carcinomas: a new clinicopathologic entity. Endocrine-Related Cancer 22 35-45. (https://doi.org/10.1530/ ERC-14-0410)

Salem ME, Puccini A, Grothey A, Raghavan D, Goldberg RM, Xiu J, Korn WM, Weinberg BA, Hwang JJ, Shields AF, et al. 2018 Landscape of tumor mutation load, Mismatch Repair Deficiency, and PD-L1 expression in a large patient cohort of gastrointestinal cancers. Molecular Cancer Research 16 805-812. (https://doi.org/10.1158/15417786.MCR-17-0735)

Salvo G, Gonzalez Martin A, Gonzales NR \& Frumovitz M 2019 Updates and management algorithm for neuroendocrine tumors of the uterine cervix. International Journal of Gynecological Cancer 29 986-995. (https://doi.org/10.1136/ijgc-2019-000504)

Schultheis AM, Scheel AH, Ozretic L, George J, Thomas RK, Hagemann T, Zander T, Wolf J \& Buettner R 2015 PD-L1 expression in small cell neuroendocrine carcinomas. European Journal of Cancer 51 421-426. (https://doi.org/10.1016/j.ejca.2014.12.006)

Shamir ER, Devine WP, Pekmezci M, Umetsu SE, Krings G, Federman S, Cho SJ, Saunders TA, Jen KY, Bergsland E, et al. 2019 Identification of high-risk human papillomavirus and Rb/E2F pathway genomic alterations in mutually exclusive subsets of colorectal neuroendocrine carcinoma. Modern Pathology 32 290-305. (https:// doi.org/10.1038/s41379-018-0131-6)
Sharabi A, Kim SS, Kato S, Sanders PD, Patel SP, Sanghvi P, Weihe E \& Kurzrock R 2017 Exceptional response to nivolumab and Stereotactic Body Radiation Therapy (SBRT) in neuroendocrine cervical carcinoma with high tumor mutational burden: management onsiderations from the Center for Personalized Cancer Therapy at UC San Diego Moores Cancer Center. Oncologist 22 631-637. (https://doi.org/10.1634/theoncologist.2016-0517)

Shen P, Jing Y, Zhang R, Cai MC, Ma P, Chen H \& Zhuang G 2018 Comprehensive genomic profiling of neuroendocrine bladder cancer pinpoints molecular origin and potential therapeutics. Oncogene 37 3039-3044. (https://doi.org/10.1038/s41388-018-0192-5)

Shia J, Tang LH, Weiser MR, Brenner B, Adsay NV, Stelow EB, Saltz LB, Qin J, Landmann R, Leonard GD, et al. 2008 Is nonsmall cell type high-grade neuroendocrine carcinoma of the tubular gastrointestinal tract a distinct disease entity? American Journal of Surgical Pathology 32 719-731. (https://doi.org/10.1097/PAS.0b013e318159371c)

Shinji S, Sasaki N, Yamada T, Koizumi M, Ohta R, Matsuda A, Yokoyama Y, Takahashi G, Hotta M, Hara K, et al. 2019 Establishment and characterization of a novel neuroendocrine carcinoma cell line derived from a human ascending colon tumor. Cancer Science 110 3708-3717. (doi:10.1111/cas.14221)

Sinha N, Gaston D, Manders D, Goudie M, Matsuoka M, Xie T \& Huang WY 2018 Characterization of genome-wide copy number aberrations in colonic mixed adenoneuroendocrine carcinoma and neuroendocrine carcinoma reveals recurrent amplification of PTGER4 and MYC genes. Human Pathology 73 16-25. (https://doi. org/10.1016/j.humpath.2017.08.036)

Sorbye H, Kong G \& Grozinsky-Glasberg S 2020 PRRT in high-grade gastroenteropancreatic neuroendocrine neoplasms (WHO G3). Endocrine-Related Cancer 27 R67-R77. (https://doi.org/10.1530/ERC19-0400)

Sorbye H, Strosberg J, Baudin E, Klimstra DS \& Yao JC 2014 Gastroenteropancreatic high-grade neuroendocrine carcinoma Cancer 120 2814-2823. (https://doi.org/10.1002/cncr.28721)

Sorbye H, Welin S, Langer SW, Vestermark LW, Holt N, Osterlund P, Dueland S, Hofsli E, Guren MG, Ohrling K, et al. 2013 Predictive and prognostic factors for treatment and survival in 305 patients with advanced gastrointestinal neuroendocrine carcinoma (WHO G3): the NORDIC NEC study. Annals of Oncology 24 152-160. (https://doi. org/10.1093/annonc/mds276)

Takizawa N, Ohishi Y, Hirahashi M, Takahashi S, Nakamura K, Tanaka M, Oki E, Takayanagi R \& Oda Y 2015 Molecular characteristics of colorectal neuroendocrine carcinoma; similarities with adenocarcinoma rather than neuroendocrine tumor. Human Pathology 46 1890-1900. (https://doi.org/10.1016/j. humpath.2015.08.006)

Tang LH, Basturk O, Sue JJ \& Klimstra DS 2016 A practical approach to the classification of WHO grade 3 (G3) well differentiated neuroendocrine tumor (WD-NET) and poorly differentiated neuroendocrine carcinoma (PD-NEC) of the pancreas. American Journal of Surgical Pathology 40 1192-1202. (https://doi.org/10.1097/ PAS.0000000000000662)

Tentler JJ, Tan AC, Weekes CD, Jimeno A, Leong S, Pitts TM, Arcaroli JJ, Messersmith WA \& Eckhardt SG 2012 Patient-derived tumour xenografts as models for oncology drug development. Nature Reviews: Clinical Oncology 9 338-350. (https://doi.org/10.1038/ nrclinonc.2012.61)

Terashima T, Morizane C, Hiraoka N, Tsuda H, Tamura T, Shimada Y, Kaneko S, Kushima R, Ueno H, Kondo S, et al. 2012 Comparison of chemotherapeutic treatment outcomes of advanced extrapulmonary neuroendocrine carcinomas and advanced small-cell lung carcinoma. Neuroendocrinology 96 324-332. (https://doi.org/10.1159/000338794)

Travis WD, Brambilla E, Burke A, Marx A \& Nicholson A 2015 WHO Classification of the Tumors of the Lung, Pleura, Thymus and Heart, 4th ed. Lyon, France: IARC Press. (c) 2020 Society for Endocrinology Published by Bioscientifica Ltd. Printed in Great Britain 
Tu X, Chang T, Nie L, Qiu S, Xu H, Huang Y, Bao Y, Liu Z, Yang L \& Wei Q 2019 Large cell neuroendocrine carcinoma of the prostate: a systematic review and pooled analysis. Urologia Internationalis $\mathbf{1 0 3}$ 383-390. (https://doi.org/10.1159/000499883)

Uccella S, Ottini G, Facco C, Maragliano R, Asioli S, Sessa F \& La Rosa S 2017 Neuroendocrine neoplasms of the head and neck and olfactory neuroblastoma. Diagnosis and classification. Pathologica 109 14-30.

Van der Laan TP, Iepsma R, Witjes MJ, van der Laan BF, Plaat BE \& Halmos GB 2016 Meta-analysis of 701 published cases of sinonasal neuroendocrine carcinoma: the importance of differentiation grade in determining treatment strategy. Oral Oncology 63 1-9. (https://doi. org/10.1016/j.oraloncology.2016.10.002)

Van der Zwan JM, Siesling S, van Velthuysen L, Links T, Walenkamp A \& Tesselaar M 2018 Extra-pulmonary neuroendocrine carcinomas: a population-based study in the Netherlands. Neuroendocrinology 107 50-59. (https://doi.org/10.1159/000488987)

Vijayvergia N, Boland PM, Handorf E, Gustafson KS, Gong Y, Cooper HS, Sheriff F, Astsaturov I, Cohen SJ \& Engstrom PF 2016 Molecular profiling of neuroendocrine malignancies to identify prognostic and therapeutic markers: a Fox Chase Cancer Center pilot study. British Journal of Cancer 115 564-570. (https://doi.org/10.1038/bjc.2016.229)

Vijayvergia N, Dasari A, Ross EA, Dotan E, Halperin DM, Astsaturov IA, Hall MJ, Ross NM, McClean D, Denlinger CS, et al. 2018 Pembrolizumab (P) monotherapy in patients with previously treated metastatic high grade neuroendocrine neoplasms (HG-NENs). Journal of Clinical Oncology 36 (Supplement 15) 4104. (https://doi. org/10.1200/JCO.2018.36.15_suppl.4104)

Vranic S, Palazzo J, Sanati S, Florento E, Contreras E, Xiu J, Swensen J \& Gatalica Z 2019 Potential novel therapy targets in neuroendocrine carcinomas of the breast. Clinical Breast Cancer 19 131-136. (https:// doi.org/10.1016/j.clbc.2018.09.001)

Walter T, Tougeron D, Baudin E, Le Malicot K, Lecomte T, Malka D, Hentic O, Manfredi S, Bonnet I, Guimbaud R, et al. 2017 Poorly differentiated gastro-entero-pancreatic neuroendocrine carcinomas: are they really heterogeneous? Insights from the FFCD-GTE national cohort. European Journal of Cancer 79 158-165. (https://doi. org/10.1016/j.ejca.2017.04.009)

Walter T, Malka D, Hentic O, Lombard-Bohas C, Le Malicot K, Smith D, Ferru A, Assenat E, Cadiot G, Lievre A, et al. 2018 Evaluating bevacizumab in combination with FOLFIRI after the failure of platinum-etoposide regimen in patients with advanced poorly differentiated neuroendocrine carcinoma: the PRODIGE 41-BEVANEC randomized phase II study. Digestive and Liver Disease 50 195-198. (https://doi.org/10.1016/j.dld.2017.11.020)

Wasserman JK, AlGhamdi D, de Almeida JR, Stockley TL \& PerezOrdonez B 2019 P53 gene mutation identified by next generation sequencing in poorly differentiated neuroendocrine carcinoma of the nasal cavity. Head and Neck Pathology 13 516-522. (https://doi. org/10.1007/s12105-018-0934-2)

Welin S, Sorbye H, Sebjornsen S, Knappskog S, Busch C \& Oberg K 2011 Clinical effect of temozolomide-based chemotherapy in poorly differentiated endocrine carcinoma after progression on first-line chemotherapy. Cancer 117 4617-4622. (https://doi.org/10.1002/ cncr.26124)

Xing D, Zheng G, Schoolmeester JK, Li Z, Pallavajjala A, Haley L, Conner MG, Vang R, Hung CF, Wu TC, et al. 2018 Next-generation sequencing reveals recurrent somatic mutations in small cell neuroendocrine carcinoma of the uterine cervix. American Journal of Surgical Pathology 42 750-760. (https://doi.org/10.1097/ PAS.0000000000001042)

Yachida S, Vakiani E, White CM, Zhong Y, Saunders T, Morgan R, de Wilde RF, Maitra A, Hicks J, Demarzo AM, et al. 2012 Small cell and large cell neuroendocrine carcinomas of the pancreas are genetically similar and distinct from well-differentiated pancreatic neuroendocrine tumors. American Journal of Surgical Pathology 36 173-184. (https://doi.org/10.1097/PAS.0b013e3182417d36)

Yao JC, Strosberg J, Fazio N, Pavel ME, Ruszniewski P, Bergsland E, Li D, Tafuto S, Raj N, Campana D, et al. 2018 Activity and safety of spartalizumab (PDR001) in patients (pts) with advanced neuroendocrine tumors (NET) of pancreatic, gastrointestinal (GI), or thoracic ( $\mathrm{T}$ ) origin, and gastroenteropancreatic neuroendocrine carcinoma (GEP NEC) who have progressed on prior treatment (Tx). Annals of Oncology 29 (Supplement 8) viii467-viii468. (https://doi. org/10.1093/annonc/mdy293.001)

Zaninotto E, Frizziero M, Durand A, Taboada RG, Luchini C, Oliveira P, Hervieu V, Claro LCL, Cingarlini S, Walter T, et al. 2020 Impact of small cell (sc) versus (vs.) non-small cell (nSC) morphology on outcomes of patients (pts) with extra-pulmonary, poorly differentiated neuroendocrine carcinoma (EP-PD-NEC). Neuroendocrinology 110 (Supplement 1) 268. (https://doi.org/10.1159/000506496)

Zatelli MC, Grossrubatscher EM, Guadagno E, Sciammarella C, Faggiano A \& Colao A 2017 Circulating tumor cells and miRNAs as prognostic markers in neuroendocrine neoplasms. Endocrine-Related Cancer 24 R223-R237. (https://doi.org/10.1530/ERC-17-0091)

Zhang P, Lu M, Li J \& Shen L 2018 Efficacy and safety of PD-1 blockade with JS001 in patients with advanced neuroendocrine neoplasms: a non-randomized, open-label, phase $1 \mathrm{~b}$ trial. Annals of Oncology 29 (Supplement 8) viii467-viii478. (https://doi.org/10.1093/annonc/ mdy293.002)

Zhuo M, Guan Y, Yang X, Hong L, Wang Y, Li Z, Chen R, Abbas HA, Chang L, Gong Y, et al. 2020 The prognostic and therapeutic role of genomic subtyping by sequencing tumor or cell-free DNA in pulmonary large-cell neuroendocrine carcinoma. Clinical Cancer Research 26 892-901. (https://doi.org/10.1158/1078-0432.CCR-19-0556)

Received in final form 3 April 2020

Accepted 1 May 2020

Accepted Manuscript published online 1 May 2020 (c) 2020 Society for Endocrinology Published by Bioscientifica Ltd. Printed in Great Britain 